\title{
Shorebird Reproductive Response to Exceptionally Early and Late Springs Varies Across Sites in Arctic Alaska
}

\section{OPEN ACCESS}

Edited by:

Mark C. Mainwaring,

University of Montana, United States

Reviewed by:

Nathan R. Senner,

University of South Carolina

United States

Erica Nol,

Trent University, Canada

David B. Lank,

Simon Fraser University, Canada

*Correspondence:

Rebecca L. McGuire

rmcguire@wcs.org

Specialty section:

This article was submitted to Behavioral and Evolutionary Ecology,

a section of the journa

Frontiers in Ecology and Evolution

Received: 29 June 2020

Accepted: 21 October 2020

Published: 09 November 2020

Citation:

McGuire RL, Lanctot RB, Saalfeld ST, Ruthrauff DR and Liebezeit JR (2020) Shorebird Reproductive Response to Exceptionally Early and Late Springs Varies Across Sites in Arctic Alaska. Front. Ecol. Evol. 8:577652. doi: 10.3389/fevo.2020.577652

\section{Rebecca L. McGuire ${ }^{1 *}$, Richard B. Lanctot ${ }^{2}$, Sarah T. Saalfeld ${ }^{2}$, Daniel R. Ruthrauff ${ }^{3}$ and Joseph R. Liebezeit ${ }^{4}$}

${ }^{1}$ Arctic Beringia Program, Wildlife Conservation Society, Fairbanks, AK, United States, ${ }^{2}$ U.S. Fish and Wildlife Service, Anchorage, AK, United States, ${ }^{3}$ U.S. Geological Survey, Alaska Science Center, Anchorage, AK, United States, ${ }^{4}$ Portland Audubon, Portland, OR, United States

While increases in overall temperatures are widely reported in the Arctic, large inter-annual variation in spring weather, with extreme early and late conditions, is also occurring. Using data collected from three sites in Arctic Alaska, we explored how shorebird breeding density, nest initiation, nest synchrony, nest survival, and phenological mismatch varied between two exceptionally early (2015 and 2016) and late (2017 and 2018) springs. We assessed these differences in the context of longterm data from each site and whether species exhibited conservative or opportunistic reproductive strategies. Conservative shorebirds typically display nest-site fidelity and territoriality, consistent population densities, relatively even individual spacing, and monogamous mating systems with bi-parental incubation. In contrast, opportunistic shorebirds display the opposite traits, and a polygamous mating system with uniparental incubation. In this study, we evaluated 2,239 nests from 13 shorebird species, 20152018, and found that shorebirds of both strategies bred earlier and in higher numbers in early, warm springs relative to historic levels (based on 3,789 nests, 2005-2014); opposite trends were observed in late springs. In early springs, nests were initiated less synchronously than in late springs. Nest survival was unrelated to spring type, but was greater in earlier laid nests overall. Invertebrate food resources emerged earlier in early springs, resulting in a greater temporal asynchrony between invertebrate emergence and chick hatching in early than late springs. However, invertebrate abundance was quite variable among sites and years regardless of spring type. Overall, our results were generally consistent with predicted relationships between spring conditions and reproductive parameters. However, we detected differences among sites that could not be explained by other ecological factors (e.g., predators or alternative prey). Differences in shorebird community composition and other subtler methodological/ecological differences among sites highlight the difficulty of understanding the complex nature of these ecological systems and the importance of evaluating questions at multiple sites across multiple years. Our study demonstrates that shorebirds exhibit a high degree of behavioral flexibility in response to variable Arctic conditions, but whether this flexibility is enough to allow them to optimally track changing environmental conditions or if evolutionary adjustments will be necessary is unknown.

Keywords: Arctic, environmental variation, nest density, nest initiation, nest survival, nest synchrony, trophic mismatch, wader 


\section{INTRODUCTION}

The timing of reproduction is a central topic in avian biology (Perrins, 1970; Drent and Daan, 1980). The general consensus is that species generally time breeding efforts to coincide with periods of high food availability (Lack, 1968). For migratory birds, the timing of such efforts relies on the successful integration of circannual and environmental cues (Gwinner, 1996). In response to recent climate warming, many migratory bird species have adjusted the timing of arrival and breeding efforts to coincide with earlier spring conditions (Crick et al., 1997; Forchhammer et al., 1998; Stenseth et al., 2002; Walther et al., 2002; Parmesan and Yohe, 2003). Other studies indicate that species that are unable to advance their arrival dates may experience negative population consequences (Møller et al., 2008; Kwon et al., 2019); arrival dates may be further constrained by migratory life history, diet, or breeding habitat (Both and Visser, 2001; Jonzén et al., 2006; Both et al., 2010). Disentangling the factors that affect the timing of avian reproductive efforts is especially complex in an era of climate warming (Miller-Rushing et al., 2010; Mortensen et al., 2016).

The ability of individuals to adjust their reproductive phenology may be especially challenging for migratory birds that breed in the Arctic. Because temperatures in the Arctic are increasing more rapidly than in other regions of the earth (Serreze and Francis, 2006; Hodgkins, 2014), environmental cues that migratory animals use to order their annual cycles may now be less reliable due to a spatial decoupling of broad-scale environmental conditions (Robinson et al., 2009; Both et al., 2010). Although long-distance migrations enable individuals to take advantage of abundant food resources, lower predation pressure, reduced competition, and lower pathogen loads found in the Arctic (Gilg and Yoccoz, 2010), Arcticbreeding birds must contend with very short breeding seasons, harsh climatic conditions, and now, rapidly changing, variable, and unpredictable environmental conditions caused by climate change (Meltofte et al., 2007a; Schmidt et al., 2019). The rapid rate of warming at northern latitudes has led to earlier, warmer, and longer summers in these regions (Richter-Menge et al., 2019). In addition, summer rainfall has increased significantly (Kattsov and Källén, 2005) and winter snowfall is predicted to increase at high latitudes (Räisänen, 2007), with as much as a $21 \%$ increase in northern Alaska by the end of the century (Littell et al., 2018). Increased snowpack may counter warming temperatures and decrease the rate of snowmelt, but it is unclear how this will alter large-scale hydrological patterns (Musselman et al., 2017). Along with a general warming pattern, both spring and summer weather has also exhibited extreme annual variation (Richter-Menge et al., 2019). As such, these new changes to annual weather conditions have the potential to greatly impact the reproductive demographics of birds in Arctic environments (Schmidt et al., 2019).

Shorebirds are one of the most diverse and abundant avian taxonomic groups of the Arctic environment, with 41 species (117 subspecies or populations) migrating to the Arctic to breed (Smith et al., 2020). Three potential demographic metrics that may be influenced by annual weather conditions are nest density, nest initiation, and nest synchrony. Shorebirds time their arrival in the Arctic after long migrations to coincide with appropriate spring environmental conditions (Meltofte et al., 2007a; Ward et al., 2016; Ely et al., 2018). Beyond the need for open habitats in which to nest, shorebirds are insectivorous, and the availability of invertebrates is critical to these species, which exploit them to sustain bodily functions, develop eggs, and for young to grow (Klaassen et al., 2001; Piersma et al., 2003; Saalfeld et al., 2019). Temperature and the timing of snowmelt affect the availability of invertebrates in Arctic ecosystems (Høye and Forchhammer, 2008; Tulp and Schekkerman, 2008; Bolduc et al., 2013; Saalfeld et al., 2019), with later snowmelt and colder temperatures equating to later activity (as terrestrial invertebrates break diapause) and emergence (adult eclosion from juvenile stages) of invertebrates due to the direct link between development and sediment temperatures (Custer and Pitelka, 1978; Butler, 1980). However, the timing of shorebird arrival in the Arctic is largely driven by environmental conditions that affect departure time from wintering sites (Rowan, 1925; Gwinner and Helm, 2003; Battley, 2006). Evidence suggests some shorebirds can delay, or even back-track, while on migration if they encounter inclement weather as they near the breeding grounds (Senner et al., 2015; Ely et al., 2018), but shorebirds are likely unable to meaningfully speed up migration if spring conditions in the Arctic are much earlier than average (Saalfeld and Lanctot, 2017). In years of severe weather and late arrival of spring, shorebirds are thought to forego breeding altogether or depart to other areas to breed (Meltofte et al., 2007a and references therein), which could alter local densities of shorebirds (Saalfeld and Lanctot, 2015, but see Robinson et al., 2014).

In years of early snowmelt, shorebirds have been shown to lay eggs shortly after arrival on the breeding grounds (Klaassen et al., 2001; Meltofte et al., 2007b), while breeding is delayed in years with later snowmelt (Smith et al., 2010; Liebezeit et al., 2014). The time between arrival and egg-laying may be determined by food availability during the pre-laying period (Meltofte et al., 2007b), as well as the availability of snow-free sites to nest (Mayfield, 1978; Smith et al., 2010). Recent studies have shown that species have advanced nest initiation dates over several decades as spring temperatures have increased (McKinnon et al., 2012; Liebezeit et al., 2014; Saalfeld and Lanctot, 2017, but see Reneerkens et al., 2016), although in most cases not sufficiently fast to keep up with earlier snowmelt. Further, nest synchrony is likely to increase if time constraints imposed by late, cold springs limit when appropriate conditions to breed are available (Nol et al., 1997; Meltofte et al., 2007b; Smith et al., 2010). Additionally, the ability to nest early may also enable species to renest should their first clutch fail, which would result in more asynchronous nesting. Thus, the breeding density and patterns of nest initiation of Arctic-breeding shorebirds are sensitive to spring conditions, but not always in predictable ways.

Spring weather conditions may also impact egg and chick survival through changes in predation rates and timing of invertebrate availability. In years with a deeper snowpack and late snowmelt, the survival of alternative prey-a term used to denote food resources, such as arvicoline rodents (lemmings and voles), 
that predators of shorebirds and their nests may alternatively consume-often increases, yielding higher abundances during spring and summer (Korslund and Steen, 2006; Kausrud et al., 2008). The presence of higher numbers of alternative prey may promote increased numbers of breeding shorebirds (Blomqvist et al., 2002; Robinson et al., 2014) and mitigate the risk of predation on their nests (Bêty et al., 2002; Smith et al., 2007; McKinnon et al., 2012, but see Weiser et al., 2018a). Persistent spring snow cover may also directly increase the predation of shorebird nests, as late-melting snow limits the area available for nesting, allowing predators to concentrate their search effort (Byrkjedal, 1980; Meltofte et al., 1981; Machín et al., 2019), and the growth of vegetative cover is phenologically delayed making nests more obvious (Laidlaw et al., 2020). However, late-melting snow may also lead to synchronous nesting that could dilute the risk of predation to any one nest (Smith et al., 2010). Because Arctic-breeding shorebirds are primarily income breeders (Klaassen et al., 2001; Piersma et al., 2003, but see Hobson and Jehl, 2010), changes in the timing and abundance of invertebrates may in turn affect shorebird nest attendance due to adult food limitations (Tulp and Schekkerman, 2006; Reneerkens et al., 2011). Adults leaving nests unattended or making more trips away from the nest may increase the likelihood of predation by reducing crypsis of the eggs (adults are better camouflaged than eggs themselves) or drawing attention to the nest (activity near a nest can reveal its location, Smith et al., 2007, 2012; Reneerkens et al., 2011; Bulla et al., 2016; Meyer et al., 2020). But evidence linking warm springs with increased nesting success is equivocal; Weiser et al. (2018a) found limited evidence for such a relationship, with only two of 14 species investigated across a broad geographic region of the Arctic having higher nest survival in warm springs. The availability of invertebrates also directly affects the ability of young to forage and survive, with mismatches between invertebrate availability and chick hatching predicted to be especially decoupled in early springs when shorebirds do not arrive early enough to time their breeding efforts with invertebrate availability (McKinnon et al., 2012; Machín et al., 2018; Kwon et al., 2019; Saalfeld et al., 2019).

Seasonal weather patterns are unlikely to affect reproductive responses of all shorebird species in the same way (Smith et al., 2010; Robinson et al., 2014; Taylor et al., 2018; Machín et al., 2019). One overarching ecological factor that might explain the ability of shorebirds to adapt to changing climatic conditions on Arctic breeding grounds is their reproductive strategy. Arctic-breeding shorebirds have previously been broadly grouped into two reproductive strategies termed 'conservative' and 'opportunistic' depending on a number of characteristics (Holmes, 1966, 1971; Pitelka et al., 1974). Conservative shorebirds typically display strong nest-site fidelity and territoriality, monogamous mating systems with bi-parental incubation and chick care, and are generally evenly spaced across appropriate habitats. On the other hand, opportunistic shorebirds typically display low nest-site fidelity, a polygamous mating system with uniparental incubation and chick care, and occur patchily and in variable numbers from year-to-year across appropriate habitats. Pitelka et al. (1974) hypothesized that by returning to the same breeding locations each year, conservative species would have an increased knowledge of local resources, allowing at least a moderate number of offspring to be produced annually, regardless of local conditions. In contrast, opportunistic shorebirds would theoretically have a greater opportunity for more offspring to be produced in some years or locations by forgoing site fidelity and instead selecting the most favorable annual breeding locations. Only two studies on shorebirds have evaluated whether being conservative or opportunistic affected breeding response to seasonal variation in environmental conditions (Saalfeld and Lanctot, 2015, 2017). They found that conservative species tended to have low variability in annual nest densities, and that there were some phenotypically flexible adjustments in most species to snowmelt, although opportunistic species appeared to adjust better than conservative species.

Clearly, the large number of factors that affect shorebird breeding parameters interact and their effects are difficult to disentangle, especially with the influence of regional and local climate change operating directly and indirectly in the background (Juhasz et al., 2020). In this study, we took advantage of two exceptionally early and late springs to evaluate how shorebirds were affected by weather conditions at three sites on the Arctic Coastal Plain of Alaska. Response to variable local conditions can provide insight to how shorebirds may adapt to future climatic conditions, allowing winners and losers of climate change and seasonal variability to be identified. We analyzed how nest density, nest initiation dates, nest synchrony, nest survival, and phenological mismatch differed between early and late springs (relative to long-term data collected over many years) within three shorebird communities as a function of their reproductive strategies. To better understand the influence of other confounding factors, we also summarized the occurrence of potential alternative prey (arvicoline rodents) and shorebird nest predators (avian and mammalian). Our goal was to identify life-history traits that may help shorebirds moderate the effects of environmental stochasticity.

We summarized our predictions of how spring weather conditions and other important interacting factors may affect Arctic-breeding shorebirds in Table 1. First, we predicted that opportunistic species would nest in higher densities during early springs and in lower densities in late springs, as low sitefidelity affords these species the opportunity to select the most favorable annual breeding locations. This prediction assumes opportunistic species have the ability to assess conditions over large geographic areas and use the timing and rate of snowmelt to make settlement decisions (Pitelka et al., 1974; Lanctot and Weatherhead, 1997; Kempenaers and Valcu, 2017). In contrast, due to their site-fidelity, we predicted that conservative species would nest at consistently similar densities to their historic levels in early springs, but in lower densities during late springs, as late springs may inhibit individuals from acquiring the necessary exogenous reserves for egg laying (Nol et al., 1997; Meltofte et al., 2007b; Smith et al., 2010). Second, we predicted earlier nest initiation dates in early springs and later initiation dates in late springs for all species. However, we predicted a greater response in these dates for opportunistic species given their greater ability to track annual spring conditions as compared to conservative species. Third, we predicted that all 
TABLE 1 | Predictions of how shorebirds would respond to early and late spring conditions by opportunistic and conservative reproductive strategies and the outcomes at Utqiagivik, Colville River, and Prudhoe Bay, 2015-2018.

\begin{tabular}{|c|c|c|c|c|c|}
\hline Factor & $\begin{array}{l}\text { Predictions for } \\
\text { conservative species }\end{array}$ & $\begin{array}{l}\text { Predictions for } \\
\text { opportunistic } \\
\text { species }\end{array}$ & Outcome Utqiaġvik & $\begin{array}{l}\text { Outcome Colville } \\
\text { River }\end{array}$ & $\begin{array}{l}\text { Outcome Prudhoe } \\
\text { Bay }\end{array}$ \\
\hline Nest density & $\begin{array}{l}\text { No change in nest } \\
\text { densities in early } \\
\text { springs but lower } \\
\text { densities in late springs }\end{array}$ & $\begin{array}{l}\text { Higher nest densities in } \\
\text { early springs, lower } \\
\text { densities in late springs }\end{array}$ & Yes & $\begin{array}{l}\text { Equivocal; both } \\
\text { conservative and } \\
\text { opportunistic species } \\
\text { had higher nest } \\
\text { densities in early } \\
\text { springs }\end{array}$ & $\begin{array}{l}\text { Equivocal; } \\
\text { opportunistic species } \\
\text { had slightly higher nest } \\
\text { densities in early } \\
\text { springs }\end{array}$ \\
\hline Nest initiation & $\begin{array}{l}\text { Marginally earlier nest } \\
\text { initiation dates in early } \\
\text { springs; marginally later } \\
\text { nest initiation dates in } \\
\text { later springs }\end{array}$ & $\begin{array}{l}\text { Earlier nest initiation } \\
\text { dates in early springs; } \\
\text { later nest initiation in } \\
\text { later springs; greater } \\
\text { response than } \\
\text { conservative species }\end{array}$ & Yes & $\begin{array}{l}\text { Equivocal; both } \\
\text { conservative and } \\
\text { opportunistic species } \\
\text { had earlier nest } \\
\text { initiation dates in early } \\
\text { springs but at similar } \\
\text { rates }\end{array}$ & $\begin{array}{l}\text { Equivocal; both } \\
\text { conservative and } \\
\text { opportunistic species } \\
\text { had earlier nest } \\
\text { initiation dates in early } \\
\text { springs but at similar } \\
\text { rates }\end{array}$ \\
\hline Nest synchrony & $\begin{array}{l}\text { Less synchrony in early } \\
\text { springs; greater } \\
\text { synchrony in late } \\
\text { springs }\end{array}$ & $\begin{array}{l}\text { Less synchrony in early } \\
\text { springs; greater } \\
\text { synchrony in late } \\
\text { springs; greater } \\
\text { response than } \\
\text { conservative species }\end{array}$ & Yes & $\begin{array}{l}\text { Yes; but conservative } \\
\text { and opportunistic } \\
\text { species had similar nest } \\
\text { synchrony }\end{array}$ & $\begin{array}{l}\text { Equivocal; conservative } \\
\text { species did not show } \\
\text { consistent results } \\
\text { between early and late } \\
\text { springs }\end{array}$ \\
\hline Nest survival & $\begin{array}{l}\text { Higher survival in early } \\
\text { springs; lower survival } \\
\text { in late springs }\end{array}$ & $\begin{array}{l}\text { Higher survival in early } \\
\text { springs; lower survival } \\
\text { in late springs }\end{array}$ & $\begin{array}{l}\text { Yes; but variable rates } \\
\text { across late springs for } \\
\text { opportunistic species }\end{array}$ & No & No \\
\hline Phenological mismatch & $\begin{array}{l}\text { Greater mismatch in } \\
\text { early springs }\end{array}$ & $\begin{array}{l}\text { Greater mismatch in } \\
\text { early springs; lower } \\
\text { response than } \\
\text { conservative species }\end{array}$ & $\begin{array}{l}\text { Equivocal; only one } \\
\text { early spring showed } \\
\text { evidence of mismatch }\end{array}$ & $\begin{array}{l}\text { Equivocal; only one } \\
\text { early spring showed } \\
\text { evidence of mismatch }\end{array}$ & -No data- \\
\hline
\end{tabular}

species would exhibit greater nest synchrony in late springs due to time constraints limiting when appropriate conditions are available. During early springs, however, we predicted reduced nest synchrony for all species, as being able to lay earlier affords individuals more time to lay both initial and replacement nests. However, as opportunistic species may be better able to respond to earlier conditions (see above), we predicted even less synchrony in opportunistic species. Fourth, we predicted lower nest survival for all species in late springs, as birds may be forced to breed in snow-free patches that are more easily searched by predators (Machín et al., 2019, notwithstanding the potential benefits of nesting synchronously) and because vegetative cover is delayed. We predicted an opposite pattern in early springs, with all species having higher nest survival. Finally, we predicted that early springs would lead to a phenological mismatch between invertebrate availability and nest hatching dates for all species, although opportunistic species might be more resilient to potential mismatches due to their greater ability to adjust to local conditions.

\section{MATERIALS AND METHODS}

We monitored seasonal weather conditions and shorebirds at three field sites in northern Alaska: Utqiagivik $\left(71^{\circ} 17^{\prime} \mathrm{N}, 156^{\circ}\right.$ $47^{\prime} \mathrm{W}$ ), Colville River $\left(70^{\circ} 26^{\prime} \mathrm{N}, 150^{\circ} 40^{\prime} \mathrm{W}\right.$ ), and Prudhoe Bay $\left(70^{\circ} 19^{\prime} \mathrm{N}, 148^{\circ} 42^{\prime} \mathrm{W}\right)$ from 2015 to 2018 . Long-term data, dating back as far as 2005 , were obtained from each site to compare to these 4 years. All three sites are located on the Arctic Coastal Plain, with the maximum distance between sites about $325 \mathrm{~km}$. All sites consist of a mosaic of low, wet marsh habitats and higher, well-drained upland habitats (Kessel and Cade, 1958; Brown et al., 1980). Utqiagivik is located at the northern most portion of Alaska (Point Barrow), and as such, has a colder, later summer on average (Taylor et al., 2018). Utqiagivik (Taylor et al., 2018) and Prudhoe Bay (Liebezeit et al., 2009) were in areas of human development, but study plots were placed $>300 \mathrm{~m}$ from roads and buildings to minimize any potential influence of human activity (see, e.g., Liebezeit et al., 2009). The Colville River site is located on the outer delta of the river (Hupp et al., 2017). All sites followed a common set of field protocols and data formats developed for the Arctic Shorebird Demographics Network (see brief descriptions below, Brown et al., 2014). Plot size varied by site, with six study plots at Utqiagivik (each $600 \times 600 \mathrm{~m}, 216$ ha total), one large plot at the Colville River that was initially 323 ha in size (2011-2016), but reduced to 262 ha in 2017, and 12 plots at Prudhoe Bay (each $100 \times 1000 \mathrm{~m}, 120$ ha total).

\section{Weather}

To assess seasonal differences in weather among years (i.e., 2015-2018), we obtained daily temperature data from the nearest meteorological station (National Climate Data Center, 2020) located at Utqiagivik (Wiley Post-Will Rogers Memorial Airport $\sim 10 \mathrm{~km}$ away from our study plots), Colville River (Colville Village located $\sim 10 \mathrm{~km}$ away), and Prudhoe Bay 
(Deadhorse Airport 2-21 km away). From these data, we calculated cumulative daily temperatures in June for each year by summing average daily temperatures (average of the minimum and maximum temperature for a given day) for each day in June. Using the same technique, we also generated longterm temperature averages for the 10 years prior to the study (i.e., 2005-2014).

We determined the loss of snow at our sites in each year by estimating the percent daily snow cover on plots every 2-5 days between late May and the end of June or until 10\% snow cover remained. Using these data, we averaged snow cover estimates across all survey locations at each site for each survey day and extrapolated estimates to dates between survey days to generate the percentage of snow cover for each day in June. When average snow cover was $<10 \%$ before the end of June, we assumed no snow remained 2 days after the last survey. Additionally, when snow surveys started after 1 June, we removed days in early June when data were not available. Using the same approach, we also generated long-term averages of snow cover for each day in June that had data for all years (i.e., Utqiagivik and Prudhoe Bay: 2005-2014, Colville River: 2011-2014).

\section{Alternative Prey and Predator Abundance}

The number of arvicoline rodents (alternative prey) and avian and mammalian predators were determined at each site and year using incidental observations each day by field staff conducting other field activities. Using these counts, we estimated the number of arvicoline rodents [voles (Microtus sp.) and lemmings (Dicrostonyx sp.)], foxes [arctic (Vulpes lagopus) and red (V. vulpes)], and avian predators [Glaucous Gull (Larus hyperboreus), Pomarine Jaeger (Stercorarius pomarinus), Parasitic Jaeger (S. parasiticus), Long-tailed Jaeger (S. longicaudus), Common Raven (Corvus corax), Sandhill Crane (Antigone canadensis), Snowy Owl (Bubo scandiacus), Short-eared Owl (Asio flammeus), Golden Eagle (Aquila chrysaetos), Peregrine Falcon (Falco peregrinus), Gyrfalcon (F. rusticolus), Northern Harrier (Circus hudsonius), Ruddy Turnstone (Arenaria interpres), and Rough-legged Hawk (Buteo lagopus)] observed per person per day by dividing the total number of individuals within each category observed in June by the average number of people in the field per day and the total number of days in June that observations occurred. For comparison, we also generated long-term (i.e., Utqiagivik: 2005-2014, Colville River: 2011-2014, Prudhoe Bay: 20102014) estimates of these abundances for June using the same techniques. Incidental counts of alternative prey such as these correlate strongly with exhaustive mark-recapture techniques used to estimate abundance (Fauteux et al., 2018). While this may not be true for some predators (e.g., counts of fox, Liebezeit and Zack, 2008), our goal was to broadly generalize the abundance of alternative prey and predators in our two early and two late springs relative to long-term counts. Doing so allowed us to better eliminate potentially confounding factors impacting our analysis of the inter-annual variation in shorebird responses.

\section{Invertebrate Availability}

To estimate invertebrate biomass at Utqiagivik and Colville River (no invertebrate data were collected at Prudhoe Bay), we used 10-16 modified "Malaise" pitfall traps equally distributed among mesic and xeric tundra habitats to capture available invertebrates throughout the nesting season. These traps consisted of a $38 \mathrm{~cm} \times 5 \mathrm{~cm} \times 7 \mathrm{~cm}$ plastic container placed at ground level that captured non-flying invertebrates, and a $36 \mathrm{~cm} \times 36 \mathrm{~cm}$ mesh screen placed perpendicular above the container to capture aerial invertebrates that hit the screen and fell into the trap (Brown et al., 2014). These traps act passively to measure both abundance and activity levels of invertebrates, and as such, have previously been used as a proxy for invertebrate availability for insectivorous birds in the Arctic (Schekkerman et al., 1998, 2003; Bolduc et al., 2013; Saalfeld et al., 2019). We typically sampled traps every 3 days between early June and late July. Individual prey items were identified to family or order and length was measured to the nearest $0.25 \mathrm{~mm}$ for individuals $<2 \mathrm{~mm}$ and to the nearest $0.5 \mathrm{~mm}$ for individuals $>2 \mathrm{~mm}$. We calculated mass for each individual using published length-mass regression equations based on taxon (Rogers et al., 1977; Schoener, 1980; Sage, 1982; Gowing and Recher, 1984; Wrubleski and Rosenberg, 1990; Sample et al., 1993; Hódar, 1996; Ganihar, 1997; Hawkins et al., 1997; Lang et al., 1997; Sabo et al., 2002). We estimated total biomass per trap day (assuming equal biomass for all days within a sampling period) for all invertebrates except large-bodied bees and wasps within the order hymenoptera. The latter are likely too large for most shorebirds to consume (Pearce-Higgins and Yalden, 2002; Schekkerman and Boele, 2009).

\section{Shorebird Reproduction Metrics}

We located shorebird nests by conducting area searches or dragging ropes across the tundra to flush adults from nests and by following birds exhibiting behaviors indicative of nesting back to their nests (Brown et al., 2014). Search effort varied between sites. At Utqiagivik, one rope drag was conducted toward the end of June and daily searches were conducted 6 days per week throughout June on each plot ( $4 \mathrm{~h}$ per day, Saalfeld and Lanctot, 2015). At the Colville River, 2-3 observers searched the study plot for 6-8 h each day during June. At Prudhoe Bay, study plots were searched for nests using alternating rope and singleperson area searches (two each) between early and late June (Bentzen et al., 2017).

We estimated nest initiation date (date first egg laid) based on the number of eggs if nests were found during egg-laying (assuming 1 egg laid per day for all taxa, although plovers may take 1.5 days, Colwell, 2006), or by back-calculating from known hatch date using standard incubation duration. If these two methods could not be used, we employed an egg-floatation technique to estimate nest initiation (Sandercock, 1998; Liebezeit et al., 2007; Brown et al., 2014). This technique relies on the fact that eggs lose mass as the embryos inside develop, causing them to sink initially and later float in water. Nests were revisited generally every 5 days during incubation. We recorded a nest as hatched if at least one chick was observed in the nest, or if eggshell fragments indicative of hatching, or an egg tooth, were found in 
the nest within 4 days of the expected hatch date (Mabee, 1997; Brown et al., 2014). We recorded the hatch date as (1) the day that downy chick(s) were first found in the nest, (2) the day after eggs were observed with pipped holes in the shells, or (3) 2 days after eggs were observed with star-cracks in the shells (Brown et al., 2014). We classified nests as unsuccessful or failed if we found broken eggshells indicative of predation in the nest, if the clutch disappeared more than 4 days before the predicted hatch date, or if the eggs remained unattended by parents for $\geq 3$ days. We recorded nest fate as unknown if there was unclear or conflicting evidence at the nest site (Brown et al., 2014). If fate was unknown ( $n=108)$, nests were considered successful until the last day they were known to be active (a metric important for the nest survival analysis). We did not include nests found at hatch for nest survival analyses.

\section{Statistical Analyses}

Based on air temperature and snow conditions, we classified each year as having a spring that was either "early" or "late" (hereafter 'spring'). We also grouped species into either a conservative or opportunistic reproductive strategy (hereafter 'strategy') based on Saalfeld and Lanctot (2015) (Table 2). In the case of the Long-billed Dowitcher, which exhibits traits of both strategies, we considered it an opportunistic breeder because of its low to nonexistent site fidelity and territoriality, which likely has the most effect on the reproductive predictions tested here (Saalfeld and Lanctot, 2015; Takekawa and Warnock, 2020).

We used general linear models (PROC MIXED, SAS Institute, Inc., Cary, NC, United States) with each nest treated as an independent data point to evaluate the categorical effects of site, year, spring, and strategy on nest initiation date. Here, we used an a priori model set consisting of all single variable models, as well as all additive and multiplicative combinations of the above variables (25 models). We used all possible model combinations in our analysis because all variables and their interactions were thought to be biologically meaningful. However, we restricted models so that year and spring did not enter the same model. We also did not include information on alternative prey, predators, and invertebrates because there was no meaningful variation (alternative prey and predators) or data was not available for all sites (invertebrates at Prudhoe Bay). Similarly, we used the same a priori model set (with the inclusion of nest initiation date as a continuous effect) and data structure to investigate variation in daily nest survival using Program MARK (White and Burnham, 1999; Dinsmore et al., 2002). For all multi-model comparisons, we used Akaike's Information Criterion corrected for small sample sizes $\left(\mathrm{AIC}_{c}\right)$, in which we considered the model with the lowest $\mathrm{AIC}_{c}$ value to be the best-supported, and models with a $\Delta \mathrm{AIC}_{c}<2$ to be plausible (Burnham and Anderson, 2002).

For each site, year, and reproductive strategy, we also calculated estimates for nest density (i.e., cumulative number of nests found throughout study plot(s) divided by the total area of the plot(s) in ha) and nest synchrony (i.e., standard deviation of nest initiation dates of the cumulative number of nests throughout study plot(s); Nol et al., 1997). When calculating nest densities, we restricted nests to those found in the smaller study plot at the Colville River across all years.

For comparison to the early and late springs that were the focus of this study, we also generated long-term estimates of nest density, nest initiation, nest synchrony, and nest survival for all years (i.e., Utqiagivik and Prudhoe Bay: 2005-2014, Colville River: 2011-2014 [small plot for nest density, and large plot for other parameters]). Here, we compared values from the early and late springs to the long-term median values to determine whether an effect was present (i.e., value was above or below the median value as predicted).

TABLE 2 | Number of shorebird nests by species located at Utqiagivik, Colville River, and Prudhoe Bay, 2015-2018.

\begin{tabular}{|c|c|c|c|c|}
\hline & Utqiaġvik & Colville River ${ }^{a}$ & Prudhoe Bay & Reproductive strategy ${ }^{b}$ \\
\hline Black-bellied Plover, Pluvialis squatarola & $0(0)$ & $25(18)$ & $1(3)$ & Cons \\
\hline American Golden-Plover, Pluvialis dominica & $40(100)$ & $0(1)$ & $4(10)$ & Cons \\
\hline Semipalmated Plover, Charadrius semipalmatus & $0(0)$ & $0(1)$ & $0(0)$ & Cons \\
\hline Bar-tailed Godwit, Limosa lapponica & $0(0)$ & $5(1)$ & $0(0)$ & Cons \\
\hline Ruddy Turnstone, Arenaria interpres & $0(1)$ & $16(26)$ & $0(1)$ & Cons \\
\hline Stilt Sandpiper, Calidris himantopus & $0(0)$ & $1(0)$ & $18(41)$ & Cons \\
\hline Dunlin, Calidris alpina & $136(336)$ & $56(55)$ & $12(24)$ & Cons \\
\hline White-rumped Sandpiper, Calidris fuscicollis & $0(6)$ & $0(0)$ & $0(0)$ & Oppor \\
\hline Buff-breasted Sandpiper, Calidris subruficollis & $0(15)$ & $0(0)$ & $2(6)$ & Oppor \\
\hline Pectoral Sandpiper, Calidris melanotos & $255(552)$ & $53(18)$ & $62(167)$ & Oppor \\
\hline Semipalmated Sandpiper, Calidris pusilla & $110(259)$ & $417(323)$ & $105(302)$ & Cons \\
\hline Western Sandpiper, Calidris mauri & $64(91)$ & $1(0)$ & $0(0)$ & Cons \\
\hline Long-billed Dowitcher, Limnodromus scolopaceus & 65 (197) & $0(2)$ & $15(20)$ & Oppor \\
\hline Red-necked Phalarope, Phalaropus Iobatus & $46(71)$ & $51(62)$ & $47(82)$ & Oppor \\
\hline Red Phalarope, Phaloropus fulicarius & $544(883)$ & 75 (69) & $13(46)$ & Oppor \\
\hline Total & $1,260(2,511)$ & $700(576)$ & $279(702)$ & \\
\hline
\end{tabular}

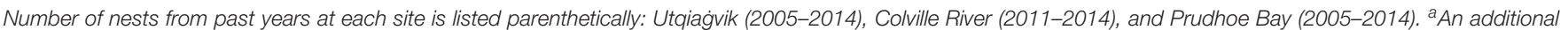
63 nests were located outside the smaller plot boundary in 2015-2018 (83 in 2011-2014) that were used for nest initiation, nest synchrony, and nest survival analyses.

${ }^{b}$ See text for definition of conservative (Cons) and opportunistic (Oppor) reproductive strategies. 

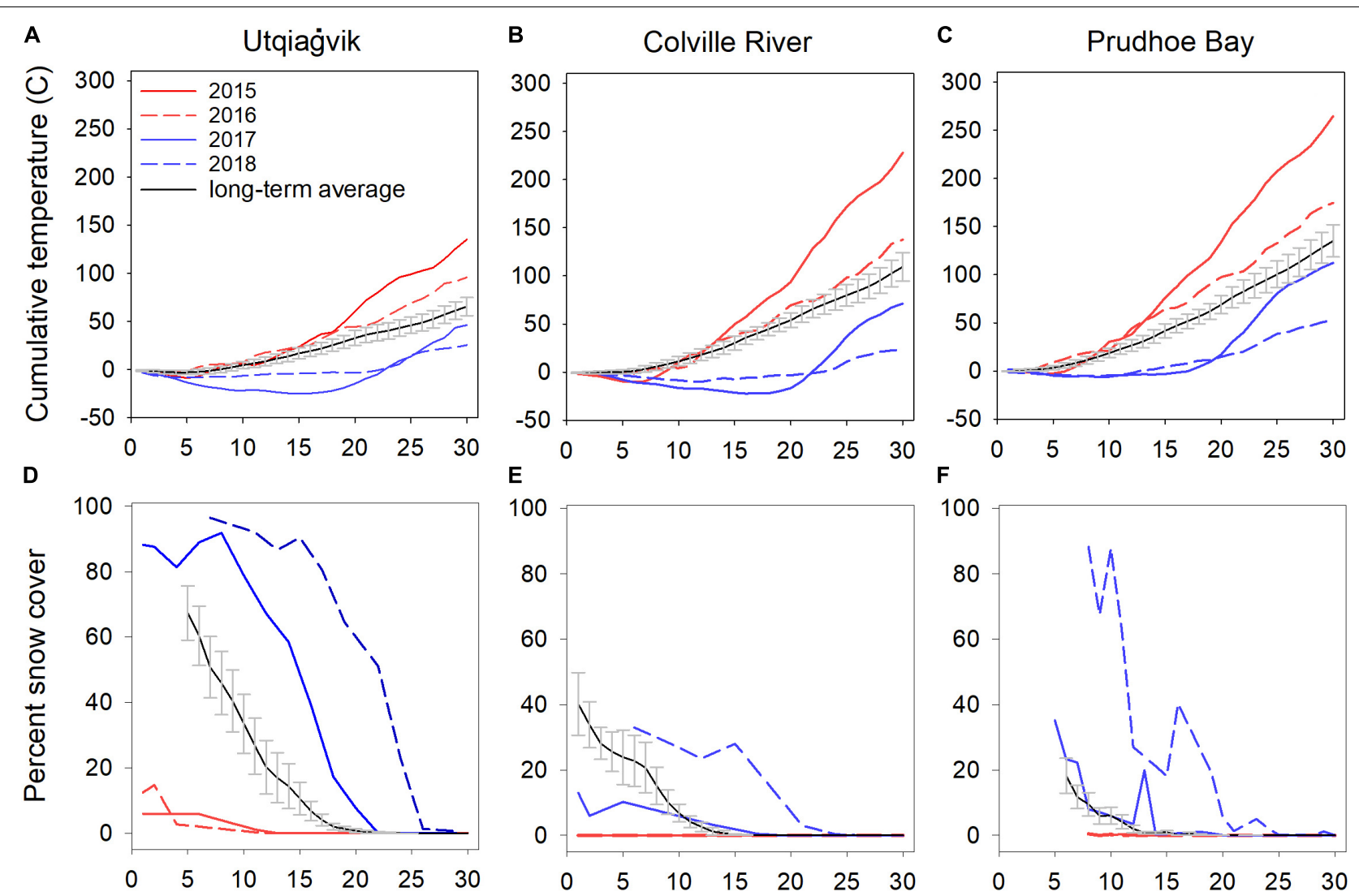

Day in June

FIGURE 1 | Cumulative daily temperatures and percent snow cover in June, 2015-2018 in relation to the long-term average \pm SE [i.e., Utqiagivik (A,D): 2005-2014 Colville River (B,E): 2005-2014 for temperature, 2011-2014 for snow cover; and Prudhoe Bay (C,F): 2005-2014]. Early springs (i.e., 2015 and 2016 ) are illustrated in red while late springs (i.e., 2017 and 2018) are illustrated in blue.

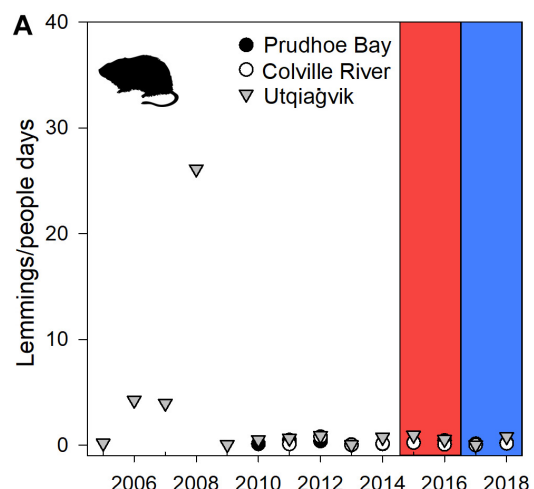

2006200820102012201420162018
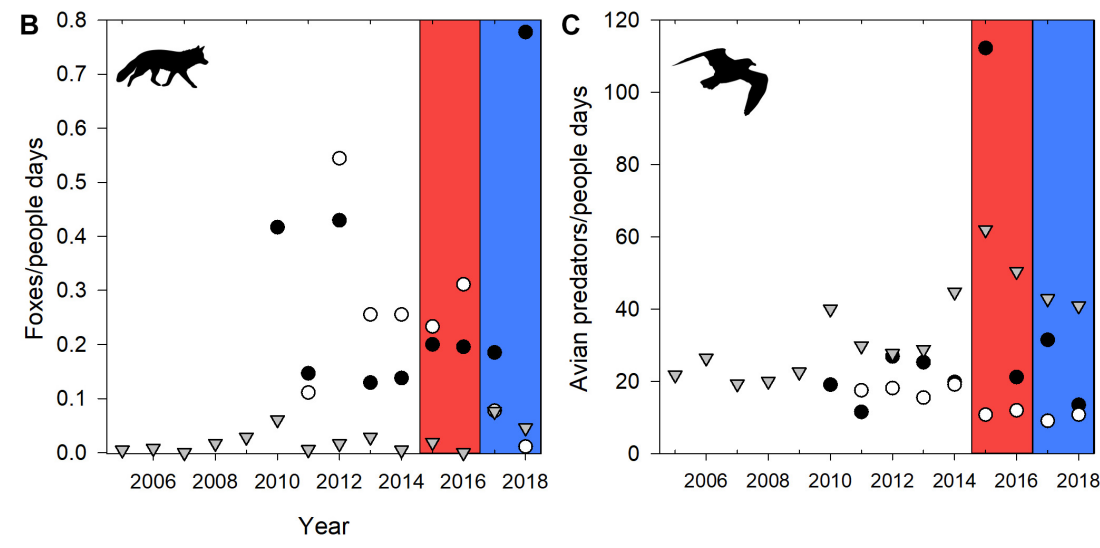

$2006200820102012 \quad 2014 \quad 2016 \quad 2018$

FIGURE 2 | Relative abundance of arvicoline rodents (A), foxes (B), and avian predators (C) in June, 2015-2018 in relation to long-term values (i.e., Utqiagivik: 2005-2014; Colville River: 2011-2014; Prudhoe Bay: 2010-2014). Fox control was in place at Utqiaġvik from 2005 to 2016. Early springs (i.e., 2015 and 2016) are illustrated in red while late springs (i.e., 2017 and 2018) are illustrated in blue.

At Utqiagvik and Colville River, we investigated phenological mismatch by graphing the area of overlap (a visual representation of the degree of phenological match) between daily invertebrate biomass and the number of broods at their peak energetic demand. To do this, we first estimated predicted hatch date of all nests, regardless of eventual fate, by assuming a 4 -egg clutch 


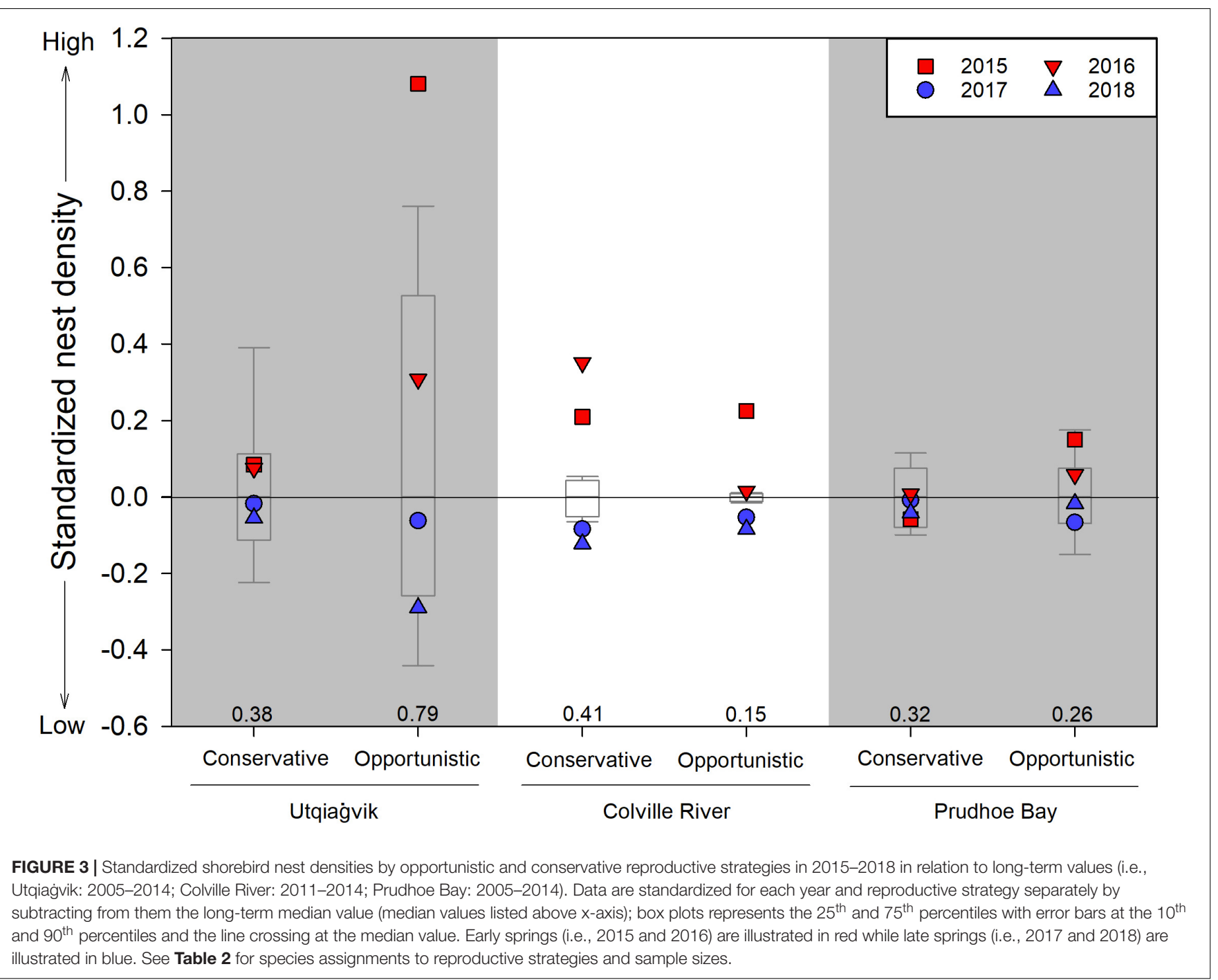

with 1 egg laid per day and standard incubation periods. Next, we estimated the number of shorebird broods at their peak energetic demand (i.e., age when chick body mass was $25 \%$ of adult body mass after Kwon et al., 2019) for each day of the field season. As our data included several species not included in Kwon et al. (2019) and with little information on growth rates, we chose to use 6 days post-hatch (middle value between 3 and 9 days used by Kwon et al. (2019)) for all species as the date of peak energetic demand. We then graphed the area of overlap between daily invertebrate biomass and the number of broods at their peak energetic demand using the same scale in all cases. All values throughout the paper are reported as means \pm standard error.

\section{RESULTS}

\section{Weather}

The years 2015 and 2016 had considerably warmer temperatures and less snow cover as compared to 2017 and 2018 across all sites (i.e., mean cumulative temperature from 1 to 30 June across sites was $209 \pm 39^{\circ} \mathrm{C}$ in $2015,136 \pm 23^{\circ} \mathrm{C}$ in $2016,77 \pm 19^{\circ} \mathrm{C}$ in 2017 , and $34 \pm 10^{\circ} \mathrm{C}$ in 2018 ; mean \% snow cover on 10 June across sites was $0.7 \pm 0.7 \%$ in $2015,0.3 \pm 0.2 \%$ in $2016,30.2 \pm 24.3 \%$ in 2017, and $69.2 \pm 21.3 \%$ in 2018; Figure 1). Additionally, 2015 and 2016 had consistently warmer temperatures and less snow cover than the long-term average, while 2017 and 2018 had consistently colder temperatures and more snow cover than the long-term average (Figure 1). Based on this, we considered 2015 and 2016 as exceptionally early springs and 2017 and 2018 as exceptionally late springs.

\section{Alternative Prey and Predator Abundance}

At all sites, the abundance of alternative prey in June was consistently low during the 2015-2018 study period (Figure 2). Fox abundance, however, was higher in 2018 at Prudhoe Bay than the first 3 years of this study, while at the Colville River, fox abundance was slightly lower in 2017 and 2018 as compared to 2015 and 2016 (Figure 2). At Utqiagivik, however, fox abundance 


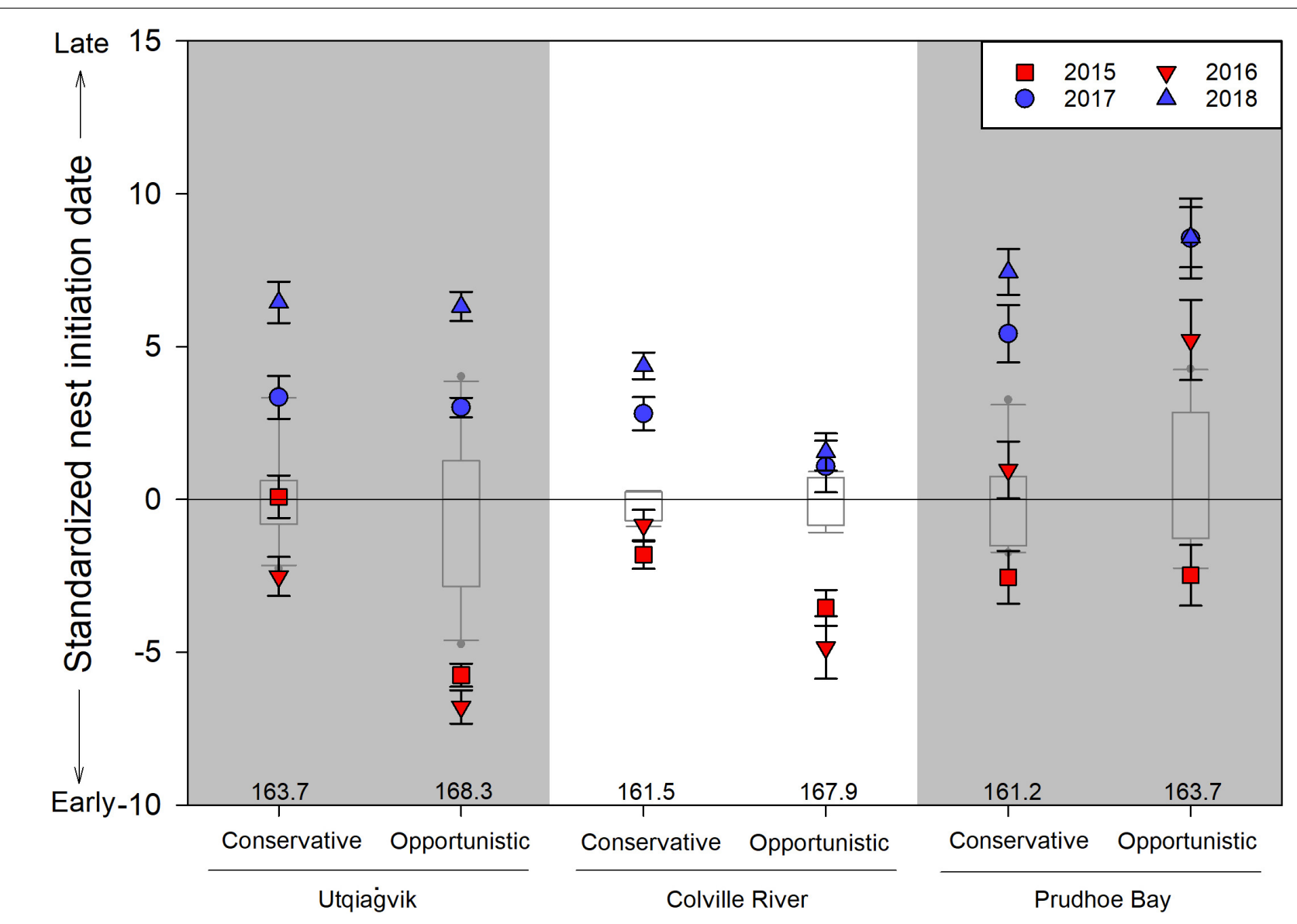

FIGURE 4 | Standardized shorebird nest initiation dates (mean \pm SE) by conservative and opportunistic reproductive strategies in $2015-2018$ in relation to long-term values (i.e., Utqiagivik: 2005-2014; Colville River: 2011-2014; Prudhoe Bay: 2005-2014). Data are standardized for each year and reproductive strategy separately by subtracting from them the long-term median value (median values listed above x-axis); box plots represent the $25^{\text {th }}$ and $75^{\text {th }}$ percentiles with error bars at the $10^{\text {th }}$ and $90^{\text {th }}$ percentiles and the line crossing at the median value. Early springs (i.e., 2015 and 2016) are illustrated in red while late springs (i.e., 2017 and 2018 ) are illustrated in blue. Julian date $150=30$ May (29 May in leap years). See Table 2 for species assignments to reproductive strategies and sample sizes.

was fairly consistent and low from 2005 to 2018 despite the fact that an active fox-control program occurred between 2005 and 2016 to promote the reproduction of Steller's Eiders (Polysticta stelleri; Barto et al., 2016). Avian predators were generally consistent within sites in the 4 years of this study, except for higher abundances in 2015 at Prudhoe Bay (Figure 2). Utqiagivik generally had 2-3 times the number of avian predators compared to the other sites (except Prudhoe Bay in 2015), with the Colville River having consistently lower numbers.

\section{Nest Densities}

Across all sites, we monitored 2,239 nests belonging to 13 species and six genera of shorebirds from 2015 to 2018, and an additional 3,789 nests belonging to 15 species and seven genera from 2005 to 2014 (Table 2). The Calidris and Phalaropus genera were the most common, followed by Limnodromus, Pluvialis, Arenaria, and Limosa. Nest densities were almost always higher in early springs (11 of 12 site/strategy cases had values above the longterm median value) and lower in late springs (12 of 12 cases) compared to long-term levels (Figure 3). The most dramatic differences were seen in opportunistic species at Utqiagivik, which were found in much higher densities in early (1.49 \pm 0.39 nests/ha) compared to late springs $(0.62 \pm 0.11)$. The Colville River site had the opposite pattern, where the most dramatic differences were seen in conservative species, which were found in much higher densities in early $(0.69 \pm 0.07)$ compared to late $(0.31 \pm 0.02)$ springs (Figure 3).

\section{Nest Initiation Dates}

Nest initiation dates were always earlier in early springs compared to late springs, regardless of the reproductive strategy (Figure 4). Furthermore, initiation dates were earlier in 9 of 12 site/strategy cases during earlier springs compared to longterm values. In contrast, initiation dates were always later in late springs (12 of 12 cases) compared to long-term values. The best-supported model mirrored these general patterns, with variation in nest initiation date best explained by the interaction between site, year, and strategy (Tables 3,$4 ; R^{2}=0.295$ ). Withinyear comparisons showed opportunistic species nested later than conservative species in 11 of 12 cases. 
TABLE 3 | Top-ranked models (plus intercept-only model) explaining variation in initiation dates of shorebird nests at Utqiaġvik, Colville River, and Prudhoe Bay, 2015-2018.

\begin{tabular}{lcccc}
\hline Model & $\boldsymbol{K}^{\mathbf{a}}$ & $\mathbf{A I C}_{\boldsymbol{c}}{ }^{\mathbf{b}}$ & $\boldsymbol{\Delta} \mathbf{A I C} \mathbf{c}^{\mathbf{c}}$ & $\boldsymbol{w}_{\boldsymbol{i}}{ }^{\mathbf{d}}$ \\
\hline Site $\times$ year $\times$ strategy & 24 & 14790.6 & 0.0 & 1.0 \\
Site $\times$ year + strategy & 13 & 14878.5 & 87.9 & 0.0 \\
Site $\times$ spring $\times$ strategy & 12 & 14892.1 & 101.5 & 0.0 \\
Year $\times$ strategy + site & 10 & 14925.5 & 134.9 & 0.0 \\
Year $\times$ strategy & 8 & 14939.4 & 148.8 & 0.0 \\
Intercept & 1 & 15613.2 & 822.6 & 0.0 \\
\hline
\end{tabular}

Variables include site, year, spring (early or late), and reproductive strategy (conservative or opportunistic). We restricted models so that year and spring did

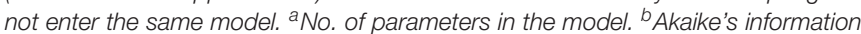
criterion corrected for small sample size. ${ }^{C}$ Difference between model $A / C_{C}$ and $A / C_{C}$ value of the best model. ${ }^{d} A / C_{C}$ relative weight attributed to model.

\section{Nest Synchrony}

In 11 of 12 strategy/site cases, shorebirds nested less synchronously during early springs compared to long-term values, and in 8 of 12 cases, nested more synchronously during late springs compared to long-term values (Figure 5). During late springs, opportunistic species nested more synchronously than conservative species at Utqiagivik and the Colville River, but not at Prudhoe Bay. In contrast, during early springs, opportunistic species nested less synchronously than conservative species at Utqiagivik and Prudhoe Bay, but not at the Colville River.

\section{Nest Survival}

Relative to long-term values, daily nest survival during late springs was lower than the long-term median values in 8 of 12 cases, while daily nest survival was greater than the long-term median values in early springs in just 3 of 12 cases (Figure 6). Similarly, our analyses found that variation in daily nest survival was best explained by a model that included site, year, initiation date, and reproductive strategy (Tables 5, 6). Based on this model, both conservative and opportunistic species had greater nest survival in early springs compared to late springs at Utqiagivik, while opposite trends or no differences between early and late springs were found at the other two sites (Figure 6). We also found that daily nest survival declined with initiation date across sites, years, and reproductive strategies $\left(\beta_{\text {initiation }}=-0.04 \pm 0.01\right.$, 95\% CI $-0.05,-0.03)$.

\section{Hatch Dates and Invertebrate Abundance}

Invertebrate availability was later in late springs than early springs, although there was large variation in the absolute abundance and phenology among years and sites (Figures 7, 8). In early springs, timing of peak food demand for the majority of both conservative and opportunistic broods occurred after peak invertebrate emergence, with less overlap between the two curves (Figures 7, 8, red area). This was especially apparent in 2015 at both Utqiagivik and the Colville River. In contrast, in late springs, the timing of peak food demand for the majority of broods occurred when invertebrate biomass was more available, with greater overlap between the two curves (Figures 7, 8, blue area).
TABLE 4 | Parameter estimates from top-ranked model (site*yearstrategy) explaining variation in initiation dates of shorebird nests at Utqiagivik, Colville River, and Prudhoe Bay, 2015-2018.

\begin{tabular}{|c|c|c|}
\hline Parameter & Estimate & SE \\
\hline Intercept ${ }^{a}$ & 172.31 & 1.21 \\
\hline Site (Utqiaġvik) & 2.31 & 1.37 \\
\hline Site (Colville River) & -2.87 & 2.03 \\
\hline Year (2015) & -11.07 & 1.53 \\
\hline Year (2016) & -3.36 & 1.62 \\
\hline Year (2017) & -0.04 & 1.85 \\
\hline Strategy (conservative) & -3.64 & 1.66 \\
\hline Site*year (Utqiaġvik²015) & -1.00 & 1.69 \\
\hline Site*year (Colville River²015) & 5.97 & 2.33 \\
\hline Site*year (Utqiaġvik²016) & -9.74 & 1.79 \\
\hline Site $^{\star}$ year (Colville River²016) & -3.03 & 2.48 \\
\hline Site $^{\star}$ year (Utqiaǵvik²017) & -3.27 & 2.02 \\
\hline Site*year (Colville River²017) & -0.44 & 2.80 \\
\hline Site*strategy (Utqiagivik*conservative) & -0.83 & 1.95 \\
\hline Site*strategy (Colville River*conservative) & 0.13 & 2.45 \\
\hline Year*strategy (2015conservative) & 1.08 & 2.24 \\
\hline Year*strategy (2016*conservative) & -3.11 & 2.25 \\
\hline Year ${ }^{\star}$ strategy $\left(2017^{\star}\right.$ conservative) & -1.98 & 2.44 \\
\hline Site*year*strategy (Utqiaġvik*2015*conservative) & 4.63 & 2.56 \\
\hline Site*yearstrategy (Colville River²015conservative) & -2.17 & 2.98 \\
\hline Site*year*strategy (Utqiaġvik²016*conservative) & 7.25 & 2.59 \\
\hline Site*year*strategy (Colville River²016*conservative) & 4.30 & 3.06 \\
\hline Site*year*strategy (Utqiaġvik²017conservative) & 2.18 & 2.80 \\
\hline Site*yearstrategy (Colville River²017*conservative) & 0.89 & 3.38 \\
\hline
\end{tabular}

Variables include site, year, and reproductive strategy (conservative or opportunistic). alntercept represents estimates for nests at Prudhoe Bay in 2018 with an opportunistic reproductive strategy.

\section{DISCUSSION}

In our multi-species assessment of the demographic response of Arctic-breeding shorebirds to variable spring conditions across three sites in Alaska, many results clearly fit our predictions and involved birds making adjustments that are perceived as adaptive responses to prevailing environmental conditions (Table 1). Such results were not wholly surprising, because our predictions were based on a wealth of prior studies investigating these relationships (see introduction). The most interesting results of this study, then, concern those that did not fit our predictions. For example, we observed strong differences among sites in the magnitude (e.g., nest density; Figure 3) and direction (e.g., nest initiation and nest synchrony responses among conservative and opportunistic species; Figures 4, 5) of certain demographic responses. Given the close proximity and similarity of habitats across our three study sites, this was unexpected. It is possible that some variation in our response variables was present due to the potential effects of fox control at Utqiagivik, human infrastructure at Prudhoe Bay and Utqiagivik, or subtle differences in other ecological variables that we did not measure (e.g., hydrology, geomorphology). Notably, inter-site variation in the abundance of alternative prey or avian and mammalian nest predators seems unlikely to have driven these patterns, because the abundance of 


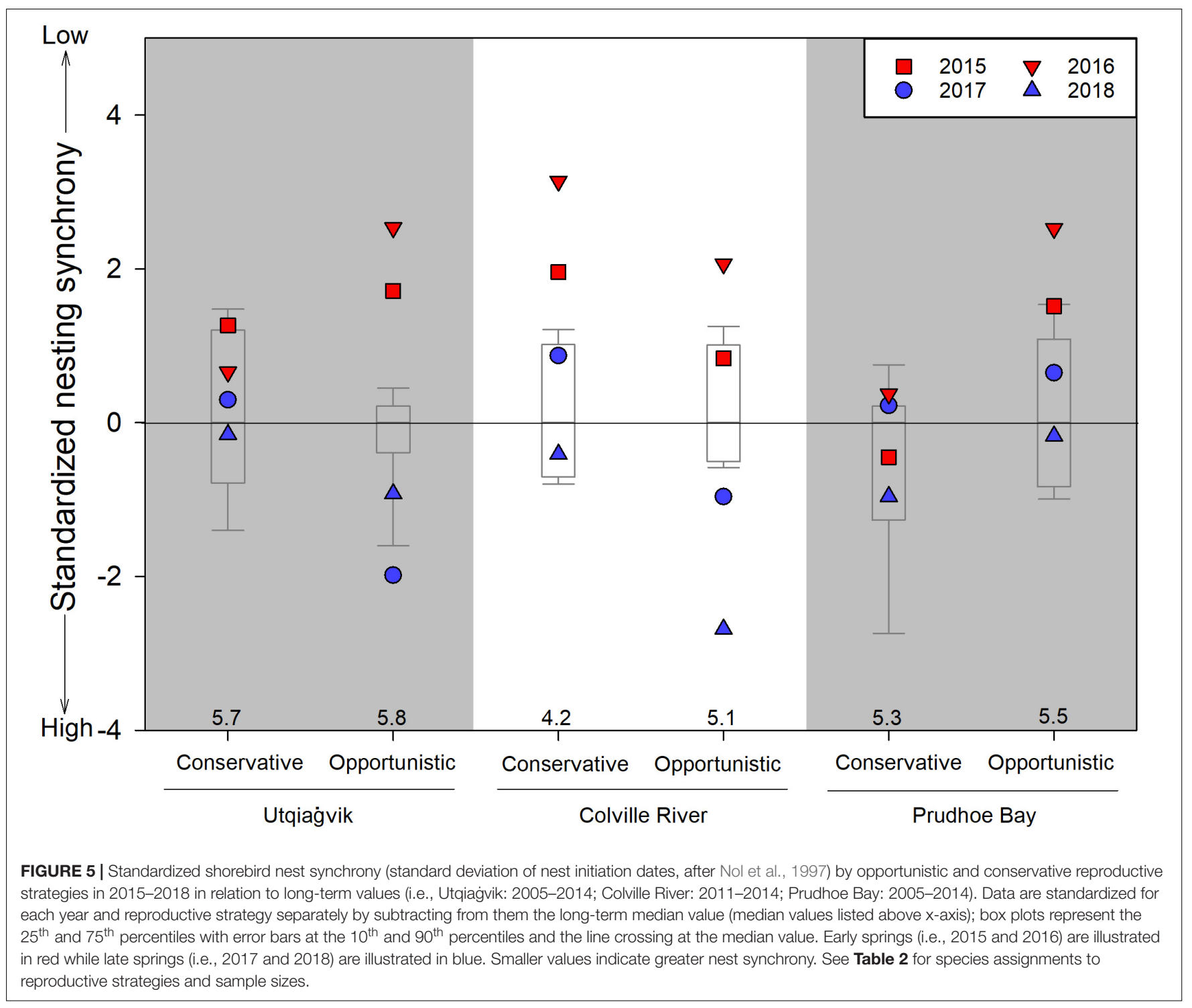

alternative prey was low at all sites in all years, and the relatively high numbers of mammalian and avian predators at some sites and years were not associated with nest survival in a consistent and predictable way (Table 1).

There were small methodological differences among the sites that might have contributed to different results among study sites. Our sites had different numbers and sizes of plots (e.g., many small linear plots versus six square plots versus one large plot), plots were searched for nests at different frequencies and with different approaches (timing, order and use of area search versus rope-drag techniques), and each site had different numbers of long-term years with which to compare the early and late spring information. These differences may influence the likelihood of finding nests (e.g., see McCaffery and Ruthrauff, 2004; Smith et al., 2009) and potentially affect perceptions of how reproductive parameters may change in early and late springs. Given the sheer number of nesting efforts monitored across these sites during our studies, however, we do not believe that these methodological differences account for magnitude of the demographic differences observed across sites. A more striking difference between the sites, however, was the difference in the shorebird community structure and the absolute numbers of particular species. For, example, opportunistic species (e.g., Red Phalarope and Pectoral Sandpiper) were dominant at Utqiagvik, while conservative species (e.g., Semipalmated Sandpiper, Dunlin) were dominant at the Colville River; the shorebird community at Prudhoe Bay was more balanced (Table 2). These differences in community composition might explain why Utqiagivik followed the predictions for opportunistic species more closely than the other sites (Table $\mathbf{1}$ ).

Our prediction that nest densities for conservative species would not change in early springs compared to the long-term median value was not supported at the Utqiagivik and Colville River sites (both sites increased between 0.08 and 0.35 nests/ha), but was supported at Prudhoe Bay (Figure 3). However, our prediction that opportunistic species would nest in higher 


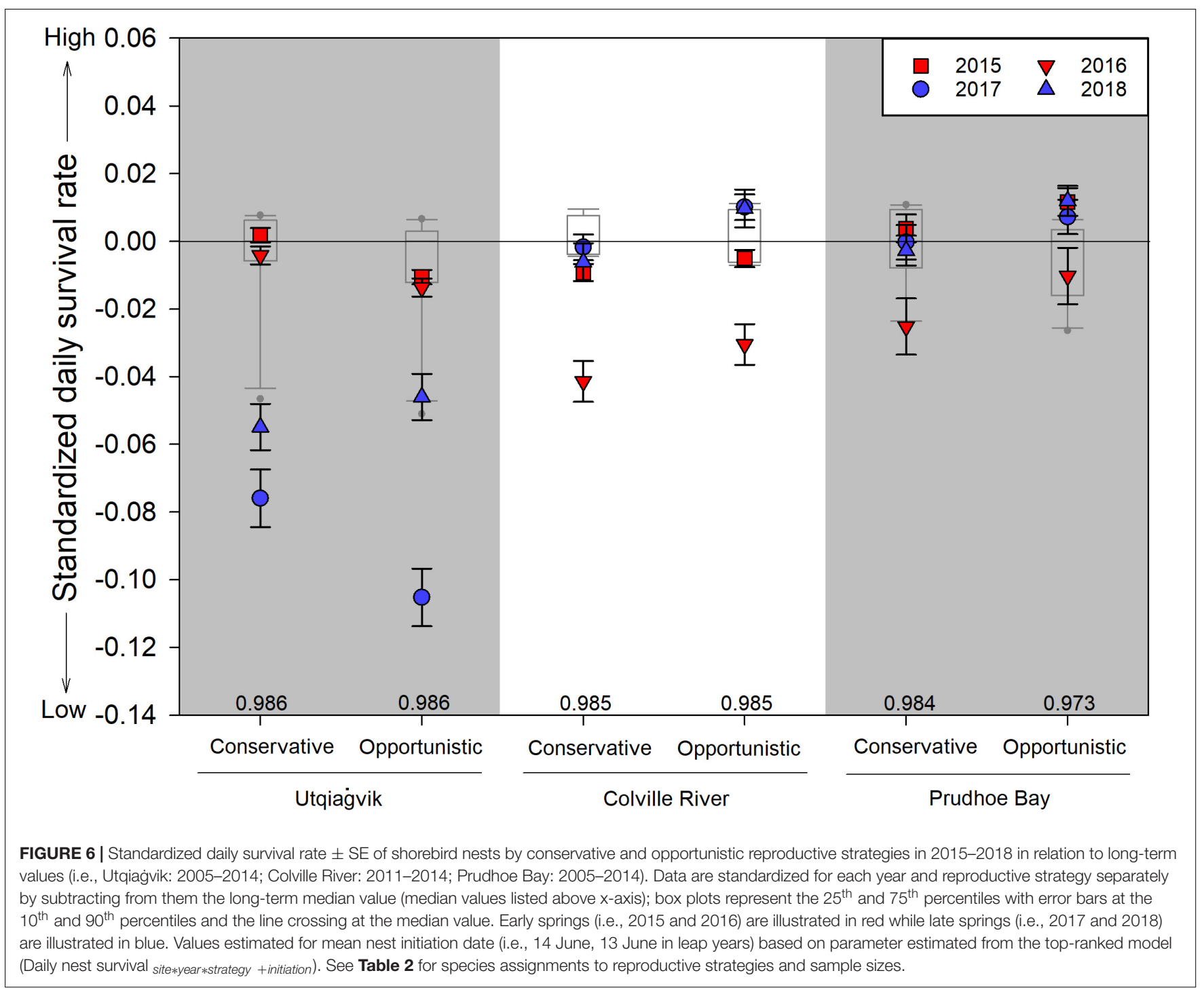

densities in early springs was met at all three study sites. This was especially notable at Utqiagvik, where nest densities of opportunistic species were 0.31 to 1.1 nests/ha greater in early springs compared to long-term levels. Some of the increase in nest density during early springs may be due to birds laying replacement nests, but this seems unlikely to account for the large increases in nest density for opportunistic species at Utqiagivik and conservative species at the Colville River. Following our prediction, both conservative and opportunistic species nested at lower densities during late springs, although the decline in nesting density was very small $(<0.29$ nests/ha) compared to long-term levels. In fact, in several years and at multiple sites, nest density was not affected at all. Changes in nest density were generally absent at Prudhoe Bay, regardless of reproductive strategy and the type of spring. While it is difficult to know the extent of replacement nesting (detailed mark-resight or paternity investigations are needed), it is likely that social cues that either limit conspecific nesting (Cunningham et al., 2016) or enhance it are important (Kempenaers and Valcu, 2017).
Most of our results support past assertions that opportunistic species are able to adjust to spring conditions better than conservative species, presumably due to their ability to assess conditions over large portions of their breeding range (Lanctot and Weatherhead, 1997; Kempenaers and Valcu, 2017). However, other assertions that birds are unable to breed during late springs due to the inability to acquire the necessary exogenous reserves (Nol et al., 1997; Meltofte et al., 2007b; Smith et al., 2010) seem less supported, as nest densities remained near long-term levels during these exceptionally late springs (except for at Utqiagvik). It is possible that the late spring conditions experienced in some of our study areas were not sufficiently poor to inhibit breeding efforts as has been reported at other sites (see, e.g., Schmidt et al., 2019).

Other studies have shown that Arctic-breeding shorebirds align the timing of nest initiation, although not always as fast as necessary, with the availability of snow-free habitats (Meltofte et al., 2007a; Smith et al., 2010; Grabowski et al., 2013; Liebezeit et al., 2014; Machín et al., 2019). Kwon et al. (2019) likewise found 
TABLE 5 | Top-ranked models (plus intercept-only model) explaining daily survival rates of shorebird nests at Utqiagivik, Colville River, and Prudhoe Bay, 2015-2018.

\begin{tabular}{|c|c|c|c|c|}
\hline Model & $K^{\mathrm{a}}$ & $\mathrm{AlC}_{c}{ }^{\mathrm{b}}$ & $\Delta \mathrm{AlC}_{c}{ }^{\mathrm{c}}$ & $w_{i}^{d}$ \\
\hline Site $\times$ year $\times$ strategy + initiation & 25 & 4887.1 & 0.0 & 0.6 \\
\hline Site $\times$ year $\times$ initiation & 24 & 4889.6 & 2.6 & 0.2 \\
\hline Site $\times$ year + initiation & 13 & 4889.9 & 2.8 & 0.1 \\
\hline Site $\times$ year + initiation + strategy & 14 & 4890.2 & 3.1 & 0.1 \\
\hline Site $\times$ year + strategy & 13 & 4927.5 & 40.4 & 0.0 \\
\hline Site $\times$ year $\times$ strategy & 24 & 4928.0 & 40.9 & 0.0 \\
\hline Site $\times$ year & 12 & 4933.3 & 46.2 & 0.0 \\
\hline Intercept & 1 & 5381.5 & 494.4 & 0.0 \\
\hline
\end{tabular}

Variables include site, year, spring (early or late), reproductive strategy (conservative or opportunistic), and nest initiation date. We restricted models so that year and spring did not enter the same model. ${ }^{a}$ No. of parameters in the model. ' ${ }^{b}$ Akaike's information criterion corrected for small sample size. ${ }^{C}$ Difference between model $A I C_{C}$ and $A I C_{C}$ value of the best model. ${ }^{d} A I C_{C}$ relative weight attributed to model.

TABLE 6 | Parameter estimates from top-ranked model (site*year*strategy + initiation) explaining variation in daily survival rates of shorebird nests at Utqiagivik, Colville River, and Prudhoe Bay, 2015-2018.

\begin{tabular}{|c|c|c|}
\hline Parameter & Estimate & SE \\
\hline Intercept (Utqiaġvik²015) & 4.27 & 0.14 \\
\hline Intercept (Utqiaġvik²016) & 4.15 & 0.15 \\
\hline Intercept (Utqiaġvik²017) & 2.58 & 0.16 \\
\hline Intercept (Utqiaġvik²018) & 3.33 & 0.19 \\
\hline Intercept (Colville River²015) & 4.46 & 0.21 \\
\hline Intercept (Colville River²016) & 3.62 & 0.23 \\
\hline Intercept (Colville River²017) & 5.86 & 0.72 \\
\hline Intercept (Colville River²018) & 5.79 & 1.01 \\
\hline Intercept (Prudhoe Bay²015) & 4.74 & 0.37 \\
\hline Intercept (Prudhoe Bay²016) & 3.83 & 0.28 \\
\hline Intercept (Prudhoe Bay²017) & 4.49 & 0.44 \\
\hline Intercept (Prudhoe Bay²018) & 4.77 & 0.38 \\
\hline Strategy (Utqiaġvik`2015conservative) & 0.73 & 0.25 \\
\hline Strategy (Utqiaġvik²016conservative) & 0.44 & 0.24 \\
\hline Strategy (Utqiaġvik²017*conservative) & 0.32 & 0.17 \\
\hline Strategy (Utqiaǵvik²018*conservative) & -0.15 & 0.19 \\
\hline Strategy (Colville River²015conservative) & -0.20 & 0.23 \\
\hline Strategy (Colville River²016conservative) & -0.23 & 0.23 \\
\hline Strategy (Colville River²017conservative) & -1.23 & 0.75 \\
\hline Strategy (Colville River²018*conservative) & -1.39 & 1.03 \\
\hline Strategy (Prudhoe Bay ${ }^{\star} 2015^{\star}$ conservative) & 0.19 & 0.62 \\
\hline Strategy (Prudhoe Bay ${ }^{\star} 2016^{\star}$ conservative) & -0.12 & 0.39 \\
\hline Strategy (Prudhoe Bay ${ }^{\star} 2017^{\star}$ conservative) & 0.17 & 0.55 \\
\hline Strategy (Prudhoe Bay²018*conservative) & -0.25 & 0.51 \\
\hline Initiation & -0.04 & 0.01 \\
\hline
\end{tabular}

Variables include site, year, reproductive strategy (conservative or opportunistic), and nest initiation date.

that despite differences in ecological and physical environments outside the breeding grounds, shorebirds at 10 sites spread across the Arctic responded to the timing of snowmelt on the breeding grounds by adjusting the timing of breeding in similar ways. None of these studies, however, assessed how reproductive strategy influenced the timing of nesting. Our prediction that birds would nest earlier in early springs and later in late springs was generally supported in this study. We found that shorebirds initiated egg laying earlier in early springs relative to longterm values in most cases (4 of 6 conservative/sites, 5 of 6 opportunistic/sites); the rest nested at the same time or later than long-term values (Figure 4). In contrast, in late springs, both conservative and opportunistic species always initiated nests later than long-term values. Within a year and site, opportunistic species nested later than conservative species in 11 of 12 cases. Thus, birds adjusted less reliably to early springs than late springs in this study, but opportunistic species always nested later than conservative species regardless of spring type. We suspect that the need to attract or compete for mates may delay nesting in opportunistic species whereas the site faithfulness of conservative species may allow them to relocate their old mate much faster (Lanctot et al., 2000). In addition, the uniparental incubation patterns present in opportunistic species may impose higher anticipatory energetic costs (Drent et al., 2006) that results in longer pre-breeding delays in nesting compared to conservative species. In contrast, conservative species that practice bi-parental incubation can anticipate more time to feed during incubation (i.e., they can lay eggs despite potentially being in worse body condition). In addition, opportunistic species may end up breeding later in late springs because their arrival is delayed due to their attempts to breed in other parts of the Arctic experiencing earlier spring conditions (Kempenaers and Valcu, 2017). The conservative species, in contrast, go to a single site and wait to initiate nests as soon as habitat opens.

Like many Arctic-breeding birds (e.g., Custer and Pitelka, 1977; Findlay and Cooke, 1982), shorebirds tend to breed synchronously, perceived both as a response to help dilute the individual risk of nest predation (Smith et al., 2010), but also to time the hatching of their young to match future peaks in food resources (Holmes and Pitelka, 1968). However, the warmer and longer breeding seasons that are a byproduct of earlier springs may lengthen the nesting period as shorebirds not only nest earlier but also have more time to renest should their first nest fail. Such a situation effectively decreases the synchrony of nesting events in early springs. While we had little information to confirm the presence of renests, prior research from Utqiagivik indicates that virtually all shorebirds renest (Naves et al., 2008) and that for Dunlin in particular, renesting can occur at a high frequency (82-95 and 35-50\% of nests whose clutches were experimentally removed during early and late incubation, respectively, subsequently renested; Gates et al., 2013). In contrast, later springs are thought to lead to more synchronous nesting, likely due to the shorter period of time in which birds have to nest (Nol et al., 1997; Meltofte et al., 2007b; Smith et al., 2010). These patterns, as outlined above and in our initial predictions, were mostly confirmed in our study, with nesting being less synchronous in early springs (11 of 12 strategy/year cases) and more synchronous in late springs (8 of 12 strategy/year cases) relative to historic levels (20052014; Figure 5). However, we did not find consistent patterns in nest synchrony between conservative and opportunistic species within years and sites. Collectively these results suggest that, at least across these three sites, the extent to which shorebirds nested 


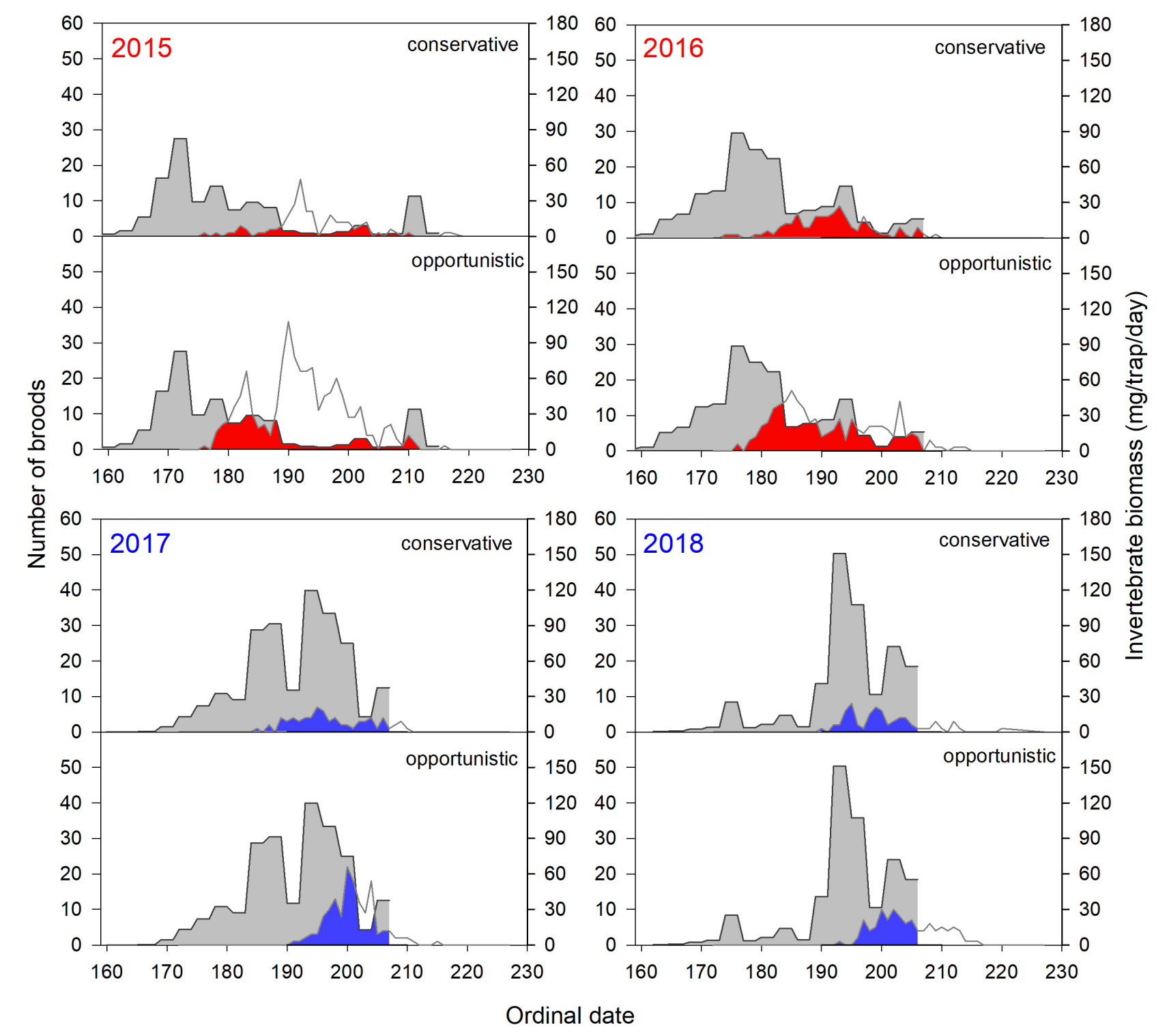

FIGURE 7 | Daily invertebrate biomass (gray) in relation to the number of conservative and opportunistic shorebird broods at peak energetic demand (i.e., 6 days post-hatch) in 2015-2018 at Utqiagivik. The area of overlap between the two curves (red in early springs 2015 and 2016 ; blue in late springs 2017 and 2018) illustrates the temporal degree of phenological match. The area outlined in white above red and blue areas reflects additional broods that were 6 days old. In most years, invertebrate sampling ended prior to the end of the brood rearing season (ordinal date 215, 207, 207, and 206 in 2015-2018, respectively); therefore, phenological match cannot be assessed for broods after these time periods. See Table 2 for species assignments to reproductive strategies and sample sizes.

synchronously was based primarily on the type of spring and not the reproductive strategy of the species.

We predicted that shorebirds would have higher nesting success in early springs compared to late springs. Contrary to our predictions, we found only a few site/year cases where these predicted relationships were followed (Figure 6). For example, as predicted, nest survival was lower in the late springs of 2017 and 2018 at Utqiagivik compared with historic levels. However, these two springs occurred after fox control was stopped in 2016, and it seems possible that higher (i.e., natural) fox densities present in subsequent years might have lowered nest survival (and not the late springs). Our consistently low counts of fox at Utqiagivik between 2005 and 2018 (Figure 2) do not support this idea, although it is possible that our opportunistic counts do not accurately reflect fox activity in the area (see Liebezeit and Zack, 2008). In most site/year cases, however, nest survival was not related to spring type in the ways that we predicted. This was particularly true for the Colville River and Prudhoe Bay sites in the early spring of 2016, when nest survival was lower than the historic levels despite having an early spring. The failure to document lower nest survival in late springs may be because the persistent snow cover not only reduced available 


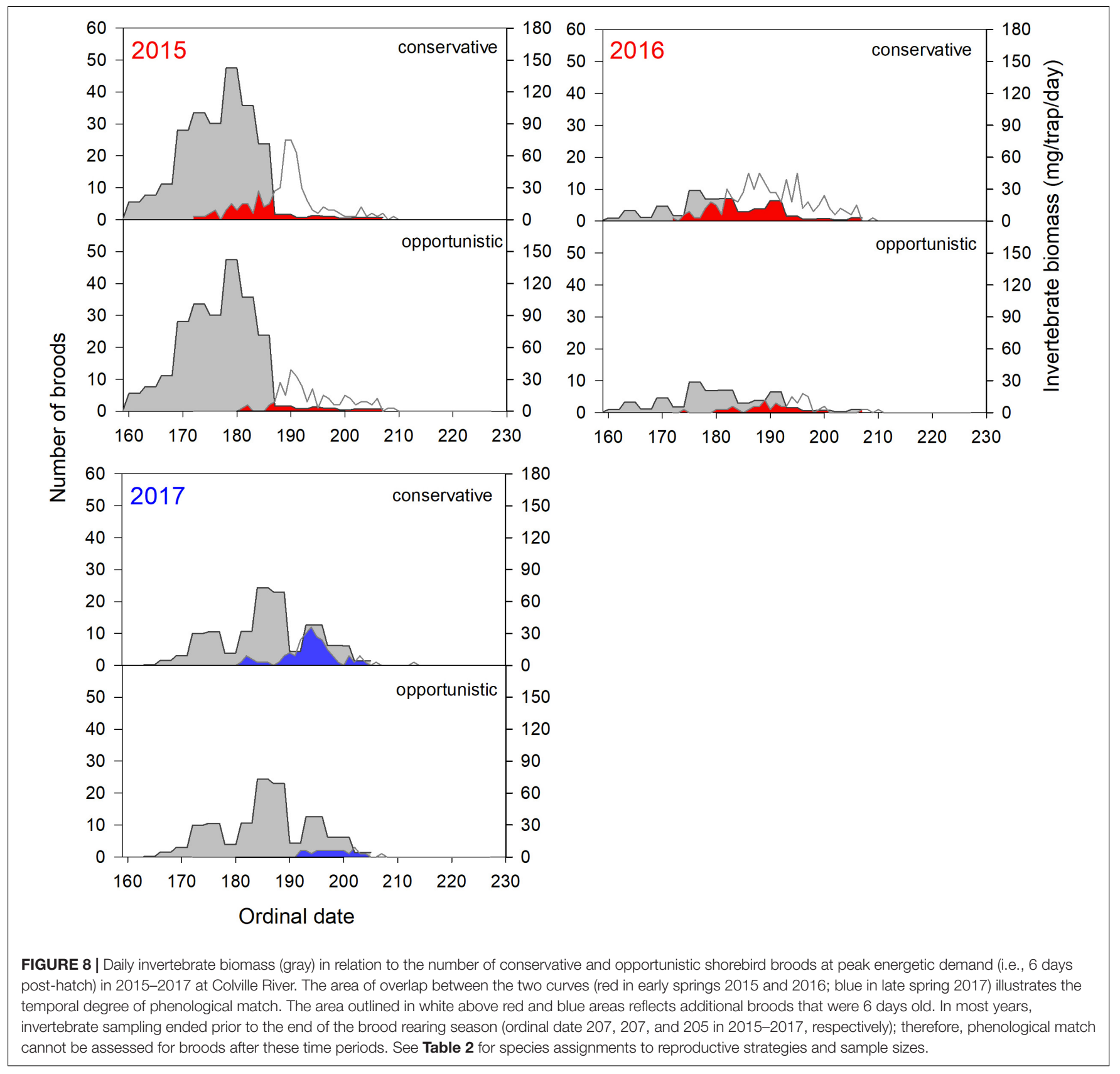

habitat for nesting (which could concentrate predation intensity) but also resulted in lower overall densities of breeding shorebirds, decreasing nest encounter rates by predators. If encounter rates are sufficiently low, foxes may choose to hunt elsewhere.

Regardless of the spring type, we found a consistent decline in daily nest survival with nest initiation date, suggesting some selective pressure exists to nest as early as possible. Failing to breed early may lead to smaller clutch sizes, less renesting, and ultimately lower adult survival (Weiser et al., 2018b), but breeding early may also be detrimental should predation intensity be greater early in the spring (Reynolds, 1987; Reneerkens et al., 2016). Interestingly, a seasonal decline in nest survival has been found in some studies (Sandercock et al., 1999; Weiser et al., 2018b), but not others (e.g., Smith and Wilson, 2010; Reneerkens et al., 2016; Senner et al., 2017), and so selection pressures likely operate differently across years and sites. This is unsurprising, given that nest survival is primarily driven by both predators and the availability of alternative prey to shorebird predators (Blomqvist et al., 2002; Smith et al., 2007; Gilg and Yoccoz, 2010; McKinnon et al., 2014; Reneerkens et al., 2016), which can vary tremendously from site to site and year to year (Liebezeit et al., 2009; Saalfeld and Lanctot, 2015).

Early springs often resulted in more broods hatching after peak food availability (Figures 7, 8). Kwon et al. (2019) also found 
that site-specific timing of snowmelt determined the extent of phenological mismatches at the population level for six species of shorebirds breeding across the North American Arctic. However, it remains unclear whether this increased temporal asynchrony is harmful to young. McKinnon et al. (2013) and Corkery et al. (2019) both reported chicks growing sufficiently well even under depressed food conditions caused by phenological mismatch, perhaps due to lower thermoregulatory needs during the warmer springs. In contrast, Saalfeld et al. (2019) found that shorebirds experienced increased phenological mismatch with earlier snowmelt, and that, in general, chicks that hatched from nests initiated earlier experienced greater food availability and grew at faster rates than chicks from nests that hatched later. Hill (2012) confirmed that insect biomass was a strong predictor of chick survival in Dunlin. Thus, it is still unclear whether hatching after peak invertebrate availability is disadvantageous, as it likely depends on overall food abundance and weather conditions during a given breeding season.

Overall, our study demonstrates that Arctic-breeding shorebirds exhibit a high degree of behavioral flexibility in response to variable Arctic conditions. Similar adaptability has been documented in a wide variety of organisms from terrestrial and marine ecosystems from around the globe (Parmesan and Yohe, 2003; Hickling et al., 2006; Chen et al., 2011; Poloczanska et al., 2013), but such adjustments have been recognized only relatively recently in shorebirds (e.g., Liebezeit et al., 2014; Kwon et al., 2019). It is necessary to determine whether existing behavioral flexibility in nesting is already sufficient to keep pace with advancing Arctic phenologies (Berteaux et al., 2004; Williams et al., 2008), or whether additional evolutionary adjustments (e.g., Hoffmann and Sgrò, 2011; Helm et al., 2019) will be required. It is important to understand these relationships given change is continuing to happen (Schmidt et al., 2019) and the potential impacts are large (see, e.g., Wauchope et al., 2016). Such information will better articulate life-history attributes that may buffer migratory birds against extreme environmental events (Williams et al., 2008).

\section{DATA AVAILABILITY STATEMENT}

The datasets presented in this study can be found in online repositories. The names of the repository/repositories and accession number(s) can be found below: "Data from the Colville

\section{REFERENCES}

Barto, L., Pratt, M. W., and Sinnett, D. (2016). Fox Control on the Barrow Steller's Eider Conservation Planning Area, 2016 Report. Unpublished report for the U.S. Fish and Wildlife Service by the U.S.D.A. Palmer, AK: Animal and Plant Health Inspection Service, 15.

Battley, P. F. (2006). Consistent annual schedules in a migratory shorebird. Biol. Lett. 2, 517-520. doi: 10.1098/rsbl.2006.0535

Bentzen, R., Dinsmore, S., Liebezeit, J., Robards, M., Streever, B., and Zack, S. (2017). Assessing development impacts on Arctic nesting birds using real and artificial nests. Polar Biol. 40, 1527-1536. doi: 10.1007/s00300-0172074-7
River used in this study are publicly available from the U.S. Geological Survey (https://doi.org/10.5066/P9BJBRTO). Data for Utqiagvik are available from the Arctic Data Center (https://doi. org/10.18739/A23R0PT35). The raw data from Prudhoe Bay will be made available by the authors upon request."

\section{ETHICS STATEMENT}

The animal study was reviewed and approved by Colville River Site: US Geological Survey/Alaska Science Center Institutional Care and Use Committee. Prudhoe Bay Site: Alaska Department of Fish and Game Institutional Care and Use Committee. Utqiagivik Site: US Fish and Wildlife Service Alaska Region Institutional Care and Use Committee.

\section{AUTHOR CONTRIBUTIONS}

RM, RL, SS, and DR conceptualized the study. RM and SS analyzed the data. RM wrote the manuscript. RL, SS, and DR contributed significantly to data interpretation and writing. All authors approved the final manuscript and collected the data.

\section{FUNDING}

Funding was provided by the USGS Changing Arctic Ecosystems initiative, the U.S. Fish and Wildlife Service, Wildlife Conservation Society, National Fish and Wildlife Foundation, Arctic Landscape Conservation Cooperative, Disney Wildlife Conservation Grant, Liz Claiborne and Art Ortenberg Foundation, Manomet, Inc., and BP Exploration (Alaska) Inc.

\section{ACKNOWLEDGMENTS}

The Ukpeagivik Iñupiat Corporation and the North Slope Borough kindly permitted us to conduct this research on their lands. We thank M. Robards, D. Ward, and S. Zack for project management, and all the many field assistants, without whom this project would not have been possible. This manuscript benefited from reviews by Chris Latty and Stephen Brown. Any use of trade, product, or firm names is for descriptive purposes only and does not imply endorsement by the U.S. Government.

Berteaux, D., Réale, D., McAdam, A. G., and Boutin, S. (2004). Keeping pace with fast climate change: can arctic life count on evolution? Integr. Comp. Biol. 44, 140-151. doi: 10.1093/icb/44.2.140

Bêty, J., Gauthier, G., Korpimaki, E., and Giroux, J. F. (2002). Shared predators and indirect trophic interactions: lemming cycles and arctic-nesting geese. J. Anim. Ecol. 71, 88-98. doi: 10.1046/j.0021-8790.2001.00581.x

Blomqvist, S., Holmgren, N., Akesson, S., Hedenstrom, A., and Pettersson, J. (2002). Indirect effects of lemming cycles on sandpiper dynamics: 50 years of counts from southern Sweden. Oecologia 133, 146-158. doi: 10.1007/s00442002-1017-2

Bolduc, E., Casajus, N., Legagneux, P., McKinnon, L., Gilchrist, H. G., Leung, M., et al. (2013). Terrestrial arthropod abundance and phenology in the Canadian 
Arctic: modeling resource availability for Arctic-nesting insectivorous birds. Can. Entomol. 145, 155-170. doi: 10.4039/tce.2013.4

Both, C., Van Turnhout, C. A. M., Bijlsma, R. G., Siepel, H., Van Strien, A. J., and Foppen, R. P. B. (2010). Avian population consequences of climate change are most severe for long-distance migrants in seasonal habitats. Proc. Royal Soc. $B$ 277, 1259-1266. doi: 10.1098/rspb.2009.1525

Both, C., and Visser, M. E. (2001). Adjustment to climate change is constrained by arrival date in a long-distance migrant bird. Nature. 411, 296-298. doi: $10.1038 / 35077063$

Brown, J., Everett, K. R., Webber, P. J., MacLean, S. F. Jr., and Murray, D. F. (1980). "The coastal tundra at Barrow,", in An Arctic Ecosystem: The Coastal Tundra at Barrow, Alaska, eds J. Brown, P. C. Miller, L. L. Tieszen, and F. L. Bunnell (Stroudsburg, PA: Dowden, Hutchinson, and Ross), 1-29.

Brown, S. C., Gates, H. R., Liebezeit, J. R., Smith, P. A., Hill, B. L., and Lanctot, R. B. (2014). Arctic Shorebird Demographics Network Breeding Camp Protocol, Version 5. Washington, DC: U.S. Fish and Wildlife Service.

Bulla, M., Valcu, M., Dokter, A. M., Dondua, A. G., Kosztolányi, A., Rutten, A., et al. (2016). Unexpected diversity in socially synchronized rhythms of shorebirds. Nature 540, 109-113.

Burnham, K. P., and Anderson, D. R. (ed.). (2002). Model Selection and Multimodel Inference: A Practical Information-Theoretic Approach, 2nd Edn, New York, NY: Springer-Verlag.

Butler, M. G. (1980). "Emergence phenologies of some Arctic Alaskan Chironomidae," in Chironomidae: Ecology, Systematics, Cytology and Physiology, ed. D. A. Murray (New York, NY: Pergamon Press), 307-314. doi: 10.1016/b978-0-08-025889-8.50048-9

Byrkjedal, I. (1980). Nest predation in relation to snow-cover - a possible factor influencing the start of breeding in shorebirds. Ornis Scand. 11, 249-252. doi: $10.2307 / 3676131$

Chen, I. C., Hill, J. K., Ohlemüller, R., Roy, D. B., and Thomas, C. D. (2011). Rapid range shifts of species associated with high levels of climate warming. Science 333, 1024-1026. doi: 10.1126/science. 1206432

Colwell, M. A. (2006). Egg-laying intervals in shorebirds. Wader Study Group Bull. $111,50-59$.

Corkery, C. A., Nol, E., and McKinnon, L. (2019). No effects of asynchrony between hatching and peak food availability on chick growth in Semipalmated Plovers (Charadrius semipalmatus) near Churchill, Manitoba. Polar Biol. 42, 593-601. doi: 10.1007/s00300-019-02456-w

Crick, H. Q. P., Dudley, C., Glue, D. E., and Thomson, D. L. (1997). UK birds are laying eggs earlier. Nature 388:526. doi: 10.1038/41453

Cunningham, J. A., Kesler, D. C., and Lanctot, R. B. (2016). Habitat and social factors influence nest site selection in Arctic-breeding shorebirds. Auk 133, 364-377. doi: 10.1642/auk-15-196.1

Custer, T. W., and Pitelka, F. A. (1977). Demographic features of a Lapland Longspur population near Barrow, Alaska. Auk 94, 505-525.

Custer, T. W., and Pitelka, F. A. (1978). Seasonal trends in summer diet of the Lapland Longspur near Barrow, Alaska. Condor 80, 295-301. doi: 10.2307/ 1368039

Dinsmore, S. J., White, G. C., and Knopf, F. L. (2002). Advanced techniques for modeling avian nest survival. Ecology 83, 3476-3488. doi: 10.1890/00129658(2002)083[3476:atfman]2.0.co;2

Drent, R. H., and Daan, S. (1980). The prudent parent: energetic adjustments in avian breeding. Ardea 55, 225-252. doi: 10.5253/arde.v68.p225

Drent, R. H., Fox, A. D., and Stahl, J. (2006). Travelling to breed. J. Orn. 147, 122-134. doi: 10.1007/s10336-006-0066-4

Ely, C. R., McCaffery, B. J., and Gill, R. E. Jr. (2018). "Shorebirds adjust spring arrival schedules with variable environmental conditions: four decades of assessment on the Yukon-Kuskokwim Delta, Alaska," in Trends and Traditions: Avifaunal Change in Western North America, eds W. D. Shuford, R. E. Gill Jr., and C. M. Handel (Camarillo, CA: Studies of Western Birds 3), 296-311. doi: $10.21199 / \mathrm{swb} 3.16$

Fauteux, D., Gauthier, G., Mazerolle, M. J., Coallier, N., Bêty, J., and Berteaux, D. (2018). Evaluation of invasive and non-invasive methods to monitor rodent abundance in the Arctic. Ecosphere 9:e02124. doi: 10.1002/ecs2. 2124

Findlay, C. S., and Cooke, F. (1982). Synchrony in the Lesser Snow Goose (Anser caerulescens caerulescens). II. The adaptive value of reproductive synchrony. Evolution 36, 786-799. doi: 10.2307/2407892

Forchhammer, M. C., Post, E., and Stenseth, N. C. (1998). Breeding phenology and climate. Nature 391, 29-30.
Ganihar, S. R. (1997). Biomass estimates of terrestrial arthropods based on body length. J. Biosci. 22, 219-224. doi: 10.1007/bf02704734

Gates, H. R., Lanctot, R. L., and Powell, A. N. (2013). High renesting rates in Arcticbreeding Dunlin (Calidris alpina). Auk 130, 372-380. doi: 10.1525/auk.2013. 12052

Gilg, O., and Yoccoz, N. G. (2010). Explaining bird migration. Science 327, 276-277. doi: 10.1126/science.1184964

Gowing, G., and Recher, H. F. (1984). Length-weight relationships for invertebrates from forests in south-eastern New South Wales. Aust. Ecol. 9, 5-8. doi: 10.1111/ j.1442-9993.1984.tb01612.x

Grabowski, M. M., Doyle, F. I., Reid, D. G., Mossop, D., and Talarico, D. (2013). Do Arctic-nesting birds respond to earlier snowmelt? A multi-species study in north Yukon, Canada. Polar Biol. 36, 1097-1105. doi: 10.1007/s00300-013$1332-6$

Gwinner, E. (1996). Circannual clocks in avian reproduction and migration. IBIS 138, 47-63. doi: 10.1111/j.1474-919x.1996.tb04312.x

Gwinner, E. G., and Helm, B. (2003). "Circannual and circadian contributions to the timing of avian migration. Endogenous timing factors in bird migration," in Avian Migration, eds P. Berthold, E. Gwinner, and E. Sonnenschein (Berlin: Springer-Verlag), 81-95. doi: 10.1007/978-3-662-05957-9_5

Hawkins, J. W., Lankester, M. W., Lautenschlager, R. A., and Bell, F. W. (1997). Length-biomass and energy relationships of terrestrial gastropods in northern forest ecosystems. Can. J. Zool. 75, 501-505. doi: 10.1139/z97-061

Helm, B., Van Doren, B. M., Hoffmann, D., and Hoffmann, U. (2019). Evolutionary response to climate change in migratory Pied Flycatchers. Curr. Biol. 29, 3714-3719. doi: 10.1016/j.cub.2019.08.072

Hickling, R., Roy, D. B., Hill, J. K., Fox, R., and Thomas, C. D. (2006). The distributions of a wide range of taxonomic groups are expanding polewards. Glob. Change Biol. 12, 450-455. doi: 10.1111/j.1365-2486.2006.01116.x

Hill, B. L. (2012). Factors Affecting Survival of Arctic-Breeding Dunlin (Calidris alpina arcticola) Adults and Chicks. Ph. D. Thesis, University of Alaska Fairbanks, Fairbanks, AK.

Hobson, K. A., and Jehl, J. R. Jr. (2010). Arctic waders and the capital-income continuum: further tests using isotopic contrasts of egg components. J. Avian Biol. 41, 565-572. doi: 10.1111/j.1600-048x.2010.04980.x

Hódar, J. A. (1996). The use of regression equations for estimation of arthropod biomass in ecological studies. Acta Ecol. 17, 421-433.

Hodgkins, R. (2014). The twenty-first-century Arctic environment: accelerating change in the atmospheric, oceanic and terrestrial spheres. Geogr. J. 180, 429-436. doi: 10.1111 /geoj. 12112

Hoffmann, A. A., and Sgrò, C. M. (2011). Climate change and evolutionary adaptation. Nature 470, 479-485.

Holmes, R. T. (1966). Breeding ecology and annual cycle adaptations of the Redbacked Sandpiper (Calidris alpina) in Northern Alaska. Condor 68, 3-46. doi: $10.2307 / 1365173$

Holmes, R. T., and Pitelka, F. A. (1968). Food overlap among coexisting sandpipers on northern Alaskan tundra. Syst. Zool. 17, 305-318. doi: 10.2307/2412009

Holmes, R. T. (1971). Density, habitat, and the mating system of the Western Sandpiper (Calidris mauri). Oecologia 7, 181-208.

Høye, T. T., and Forchhammer, M. C. (2008). The influence of weather conditions on the activity of high-arctic arthropods inferred from long-term observations. BMC Ecol. 8:8. doi: 10.1186/1472-6785-8-8

Hupp, J. W., Ward, D. H., Hogrefe, K. R., Sedinger, J. S., Martin, P. D., Stickney, A. A., et al. (2017). Growth of black brant and lesser snow goose goslings in northern Alaska. J. Wildl. Manage. 81, 846-857. doi: 10.1002/jwmg.21246

Jonzén, N., Lindén, A., Ergon, T., Knudsen, E., Vik, J. O., Rubolini, D., et al. (2006). Rapid advances of spring arrival dates in long-distance migratory birds. Science 312, 1959-1961. doi: 10.1126/science.1126119

Juhasz, C.-C., Shipley, B., Gauthier, G., Berteaux, D., and Lecomte, N. (2020). Direct and indirect effects of regional and local climatic factors on trophic interactions in the Arctic tundra. J. Anim. Ecol. 89, 704-715. doi: 10.1111/1365-2656.13104

Kattsov, V. M., and Källén, E. (2005). "Future climate change: modeling and scenarios for the Arctic," in Arctic Climate Impact Assessment, eds C. Symon, L. Arris, and B. Heal (Cambridge: Cambridge University Press), 101-150.

Kausrud, K. L., Mysterud, A., Steen, H., Vik, J. O., Østbye, E., Cazelles, B., et al. (2008). Linking climate change to lemming cycles. Nature 456, 93-97. doi: 10.1038 /nature 07442

Kempenaers, B., and Valcu, M. (2017). Breeding site sampling across the Arctic by individual males of a polygynous shorebird. Nature 541, 528-531. doi: $10.1038 /$ nature20813 
Kessel, B., and Cade, T. J. (1958). Birds of the Colville River, Northern Alaska. Biological Papers of the University of Alaska no. 2. College, AK: University of Alaska.

Klaassen, M., Lindstrom, A., Meltofte, H., and Piersma, T. (2001). Arctic waders are not capital breeders. Nature 413, 794-794. doi: 10.1038/35101654

Korslund, L., and Steen, H. (2006). Small rodent winter survival: snow conditions limit access to food resources. J. Anim. Ecol. 75, 156-166. doi: 10.1111/j.13652656.2005.01031.x

Kwon, E., Weiser, E. L., Lanctot, R. B., Brown, S. C., Gates, H. R., Gilchrist, G., et al. (2019). Geographic variation in the intensity of warming and phenological mismatch between Arctic shorebirds and invertebrates. Ecol. Monogr. 84:e01383.

Lack, D. (1968). Ecological Adaptations for Breeding in Birds, Vol. 86. London: Methuen, 774-777. doi: 10.2307/4083484

Laidlaw, R. A., Gunnarsson, T. G., Mendez, V., Carneiro, C., porrison, B., Wentworth, A., et al. (2020). Vegetation structure influences predation rates of early nests in subarctic breeding waders. IBIS 162, 1225-1236. doi: 10.1111/ ibi. 12827

Lanctot, R. B., Sandercock, B. K., and Kempenaers, B. (2000). Do male breeding displays function to attract mates or defend territories? The explanatory role of mate and site fidelity. Waterbirds. 23, 155-164.

Lanctot, R. B., and Weatherhead, P. J. (1997). Ephemeral lekking behavior in the Buff-breasted Sandpiper, Tryngites subruficollis. Behav. Ecol. 8, 268-278. doi: 10.1093/beheco/8.3.268

Lang, A., Kroob, S., and Stumpf, H. (1997). Mass-length relationships of epigeal arthropod predators in arable land (Araneae, Chilopoda, Coleoptera). Pedobiologia 41, 327-333.

Liebezeit, J. R., Gurney, K. E. B., Budde, M., Zack, S., and Ward, D. (2014). Phenological advancement in arctic bird species: relative importance of snow melt and ecological factors. Polar Biol. 37, 1309-1320. doi: 10.1007/s00300014-1522-x

Liebezeit, J. R., Kendall, S. J., Brown, S., Johnson, C. B., Martin, P., McDonald, T. L., et al. (2009). Influence of human development and predators on nest survival of tundra birds, Arctic Coastal Plain, Alaska. Ecol. Appl. 19, 1628-1644. doi: 10.1890/08-1661.1

Liebezeit, J. R., Smith, P. A., Lanctot, R. B., Schekkerman, H., Kendall, S. J., Tracy, D. M., et al. (2007). Assessing the development of shorebird eggs using the flotation method: species-specific and generalized regression models. Condor 109, 32-47. doi: 10.1650/0010-5422(2007)109[32:atdose]2.0.co;2

Liebezeit, J. R., and Zack, S. (2008). Point counts underestimate the importance of arctic foxes as avian nest predators: evidence from remote video cameras in arctic Alaskan oil fields. Arctic 61, 153-161.

Littell, J. S., McAfee, S. A., and Hayward, G. D. (2018). Alaska snowpack response to climate change: statewide snowfall equivalent and snowpack water scenarios. Water 10:668. doi: 10.3390/w10050668

Mabee, T. J. (1997). Using eggshell evidence to determine nest fate of shorebirds. Wilson Bull. 109, 307-313.

Machín, H. F., Fernández-Elipe, J., Hungar, J., Angerbjörn, A., Klaassen, R. H. G., and Aguirre, J. I. (2019). The role of ecological and environmental conditions on the nesting success of waders in sub-Arctic Sweden. Polar Biol. 42, 1571-1579. doi: 10.1007/s00300-019-02544-x

Machín, H. F., Fernández-Elipe, J., and Klaassen, R. H. G. (2018). The relative importance of food abundance and weather on the growth of a sub-arctic shorebird chick. Behav. Ecol. Sociobiol. 72:42.

Mayfield, H. F. (1978). Undependable breeding conditions in the red phalarope. Auk 95, 590-592.

McCaffery, B. J., and Ruthrauff, D. R. (2004). How intensive is intensive enough? Limitations of intensive searching for estimating shorebird numbers. Wader Stud. Group Bull. 103, 63-66.

McKinnon, L., Berteaux, D., and Béty, J. (2014). Predator-mediated interactions between lemmings and shorebirds: a test of the alternative prey hypothesis. Auk 131, 619-628. doi: 10.1642/auk-13-154.1

McKinnon, L., Bolduc, E., and Bêty, J. (2012). Timing of breeding, peak food availability, and effects of mismatch on chick growth in birds nesting in the high Arctic. Can. J. Zool. 90, 961-971. doi: 10.1139/z2012064

McKinnon, L., Nol, E., and Juillet, C. (2013). Arctic-nesting birds find physiological relief in the face of trophic constraints. Sci. Rep. 3:1816.
Meltofte, H., Hoye, T. T., Schmidt, N. M., and Forchhammer, M. C. (2007b). Differences in food abundance cause inter-annual variation in the breeding phenology of High Arctic waders. Polar Biol. 30, 601-606. doi: 10.1007/s00300006-0219-1

Meltofte, H., Elander, M., and Hjort, C. (1981). Ornithological observations in northeast Greenland between $74^{\circ} 30^{\prime}$ and $76^{\circ} 80^{\prime} \mathrm{N}$. lat. - Meddelelser om Grønland. Bioscience 3, 52.

Meltofte, H., Piersma, T., Boyd, H., McCaffery, B., Ganter, B., Golovnyuk, V. V., et al. (2007a). Effects of Climate Variation on the Breeding Ecology of Arctic Shorebirds. Meddelelser om Grønland Bioscience 59. Copenhagen: Danish Polar Center.

Meyer, N., Bollache, L., Dechaume-Moncharmont, F.-X., Moreau, J., Afonso, E., Angerbjörn, A., et al. (2020). Nest attentiveness drives nest predation in Arctic Sandpipers. Oikos 129, 1481-1492. doi: 10.1111/oik.07311

Miller-Rushing, A. J., Høye, T. T., Inouye, D. W., and Post, E. (2010). The effects of phenological mismatches on demography. Philos. Trans. R. Soc. Lond. B Biol. Sci. 365, 3177-3186. doi: 10.1098/rstb.2010.0148

Møller, A. P., Rubolini, D., and Lehikoinen, E. (2008). Populations of migratory bird species that did not show a phenological response to climate change are declining. Proc. Natl. Acad. Sci. U.S.A. 105, 16195-16200. doi: 10.1073/pnas. 0803825105

Mortensen, L. O., Schmidt, N. M., Høye, T. T., Damgaard, C., and Forchhammer, M. C. (2016). Analysis of trophic interactions reveals highly plastic response to climate change in a tri-trophic High-Arctic ecosystem. Polar Biol. 39, 14671478. doi: $10.1007 /$ s00300-015-1872-z

Musselman, K. N., Clark, M. P., Liu, C., Ikeda, K., and Rasmussen, R. (2017). Slower snowmelt in a warmer world. Nat. Clim. Chang. 7, 214-219. doi: 10. 1038/nclimate3225

National Climate Data Center (2020). Period of Record Daily Climate Summaries. Asheville: NCDC.

Naves, L. C., Lanctot, R. B., Taylor, A. R., and Coutsoubos, N. P. (2008). How often do Arctic shorebirds lay replacement clutches? Wader Stud. Group Bull. 115, $2-9$.

Nol, E., Blanken, M. S., and Flynn, L. (1997). Sources of variation in clutch size, egg size and clutch completion dates of Semipalmated Plovers in Churchill, Manitoba. Condor 99, 389-396. doi: 10.2307/1369945

Parmesan, C., and Yohe, G. (2003). A globally coherent fingerprint of climate change impacts across natural systems. Nature 421, 37-42. doi: 10.1038/ nature 01286

Pearce-Higgins, J. W., and Yalden, D. W. (2002). Variation in the growth and survival of Golden Plover Pluvialis apricaria chicks. IBIS 144, 200-209. doi: 10.1046/j.1474-919x.2002.00048.x

Perrins, C. M. (1970). The timing of birds' breeding seasons. IBIS 112, 242-255. doi: 10.1111/j.1474-919x.1970.tb00096.x

Piersma, T., Lindstrom, A., Drent, R. H., Tulp, I., Jukema, J., Morrison, R. I. G., et al. (2003). High daily energy expenditure of incubating shorebirds on High Arctic tundra: a circumpolar study. Funct. Ecol. 17, 356-362. doi: 10.1046/j. 1365-2435.2003.00741.x

Pitelka, F. A., Holmes, R. T., and MacLean, S. F. (1974). Ecology and Evolution of social organization in Arctic sandpipers. Am. Zool. 14, 185-204. doi: 10.1093/ icb/14.1.185

Poloczanska, E. S., Brown, C. J., Sydeman, W. J., Kiessling, W., Schoeman, D. S., Moore, P. J., et al. (2013). Global imprint of climate change on marine life. Nat. Clim. Change 3, 919-925.

Räisänen, J. (2007). Warmer climate: less or more snow? Clim. Dyn. 30, 307-319. doi: 10.1007/s00382-007-0289-y

Reneerkens, J., Grond, K., Schekkerman, H., Tulp, I., and Piersma, T. (2011). Do uniparental sanderlings Calidris alba increase egg heat input to compensate for low nest attentiveness? PLoS One 6:e16834. doi: 10.1371/journal.pone.0016834

Reneerkens, J., Schmidt, N. M., Gilg, O., Hansen, J., and Hansen, L. H. (2016). Effects of food abundance and early clutch predation on reproductive timing in a high Arctic shorebird exposed to advancements in arthropod abundance. Ecol. Evol. 6, 7375-7386. doi: 10.1002/ece3.2361

Reynolds, J. D. (1987). Mating system and nesting biology of the red-necked phalarope Phalaropus lobatus: what constrains polyandry? IBIS 129, 225-242. doi: 10.1111/j.1474-919x.1987.tb03203.x

Richter-Menge, J., Druckenmiller, M. L., and Jeffries, M. (2019). Arctic Report Card 2019. Washington, DC: NOAA. 
Robinson, B. G., Franke, A., and Derocher, A. E. (2014). The influence of weather and lemmings on spatiotemporal variation in the abundance of multiple avian guilds in the Arctic. PLoS One 9:e101495. doi: 10.1371/journal.pone.0101495

Robinson, R. A., Crick, H. Q. P., Learmonth, J. A. I, Maclean, M. D., Thomas, C. D., Bairlein, F., et al. (2009). Travelling through a warming world: climate change and migratory species. Endanger. Species Res. 7, 87-99. doi: 10.3354/esr00095

Rogers, L. E., Buschbom, R. L., and Watson, C. R. (1977). Length-weight relationships of shrub-steppe invertebrates. Ann. Entomol. Soc. Am. 70, 51-53. doi: 10.1093/aesa/70.1.51

Rowan, W. (1925). Relation of light to bird migration and developmental changes. Nature 115, 494-495. doi: 10.1038/115494b0

Saalfeld, S. T., and Lanctot, R. B. (2015). Conservative and opportunistic settlement strategies in Arctic-breeding shorebirds. Auk 132, 212-234. doi: 10.1642/auk13-193.1

Saalfeld, S. T., and Lanctot, R. B. (2017). Multispecies comparisons of adaptability to climate change: a role for life-history characteristics? Ecol. Evol. 7, 1049210502. doi: 10.1002/ece3.3517

Saalfeld, S. T., McEwen, D. C., Kesler, D. C., Butler, M. G., Cunningham, J. A., Doll, A. C., et al. (2019). Phenological mismatch in Arctic-breeding shorebirds: impact of snowmelt and unpredictable weather conditions on food availability and chick growth. Ecol. Evol. 9, 6693-6707. doi: 10.1002/ece3.5248

Sabo, J. L., Bastow, J. L., and Power, M. E. (2002). Length-mass relationships for adult aquatic and terrestrial invertebrates in a California watershed. J. North Am. Benthol. Soc. 21, 336-343. doi: 10.2307/1468420

Sage, R. D. (1982). Wet and dry-weight estimates of insects and spiders based on length. Am. Midl. Nat. 108, 407-411. doi: 10.2307/2425505

Sample, B. E., Cooper, R. J., Greer, R. D., and Whitmore, R. C. (1993). Estimation of insect biomass by length and width. Am. Midl. Nat. 129, 234-240. doi: $10.2307 / 2426503$

Sandercock, B. K. (1998). Chronology of nesting events in Western and Semipalmated Sandpipers near the Arctic Circle. J. Field Ornithol. 69, 235-243.

Sandercock, B. K., Lank, D. B., and Cooke, F. (1999). Seasonal declines in the fecundity of arctic-breeding sandpipers: different tactics in two species with an invariant clutch size. J. Avian Biol. 30, 460-468. doi: 10.2307/3677018

Schekkerman, H., and Boele, A. (2009). Foraging in precocial chicks of the Blacktailed Godwit Limosa limosa: vulnerability to weather and prey size. J. Avian Biol. 40, 369-379. doi: 10.1111/j.1600-048x.2008.04330.x

Schekkerman, H., Tulp, I., Piersma, T., and Visser, G. H. (2003). Mechanisms promoting higher growth rate in Arctic than in temperate shorebirds. Oecologia 134, 332-342. doi: 10.1007/s00442-002-1124-0

Schekkerman, H., van Roomen, M. W. J., and Underhill, L. G. (1998). Growth, behaviour of broods and weather-related variation in breeding productivity of Curlew Sandpipers Calidris ferruginea. Ardea 86, 153-168.

Schmidt, N. M., Reneerkens, J., Christensen, J. H., Olesen, M., and Roslin, T. (2019). An ecosystem-wide reproductive failure with more snow in the Arctic. PLoS Biol 17:e3000392. doi: 10.1371/journal.pbio.3000392

Schoener, T. W. (1980). Length-weight regressions in tropical and temperate forestunderstory insects. Ann. Entomol. Soc. Am. 73, 106-109. doi: 10.1093/aesa/73. 1.106

Senner, N. R., Stager, M., and Sandercock, B. K. (2017). Ecological mismatches are moderated by local conditions for two populations of a long-distance migratory bird. Oikos 126, 61-72. doi: 10.1111/oik.03325

Senner, N. R., Verhoeven, M. A., Abad-Gomez, J. M., and Gutierrez, J. S. (2015). When Siberia came to the Netherlands: the response of continental blacktailed godwits to a rare spring weather event. J. Anim. Ecol. 84, 1164-1176. doi: 10.1111/1365-2656.12381

Serreze, M. C., and Francis, J. A. (2006). The Arctic amplification debate. Clim. Change 76, 241-264. doi: 10.1007/s10584-005-9017-y

Smith, P. A., Bart, J., Lanctot, R. B., McCaffery, B. J., and Brown, S. (2009). Probability of detection of nests and implications for survey design. Condor 111, 414-423. doi: 10.1525/cond.2009.090002

Smith, P. A., and Wilson, S. (2010). Intraseasonal patterns in shorebird nest survival are related to nest age and defence behaviour. Oecologia 163, 613-624. doi: 10.1007/s00442-010-1644-y

Smith, P. A., Gilchrist, H. G., Forbes, M. R., Martin, J.-L., and Allard, K. (2010). Inter-annual variation in the breeding chronology of arctic shorebirds: effects of weather, snow melt and predators. J. Avian Biol. 41, 292-304. doi: 10.1111/j. 1600-048x.2009.04815.x
Smith, P. A., Gilchrist, H. G., and Smith, J. N. M. (2007). Effects of nest habitat, food, and parental behavior on shorebird nest success. Condor 109, 15-31. doi: 10.1650/0010-5422(2007)109[15:eonhfa]2.0.co;2

Smith, P. A., McKinnon, L., Meltofte, H., Lanctot, R. B., Fox, A. D., Leafloor, J. O., et al. (2020). Status and trends of tundra birds across the Circumpolar Arctic. Ambio 49, 732-748. doi: 10.1007/s13280-019-01308-5

Smith, P. A., Tulp, I., Schekkerman, H., Gilchrist, H. G., and Forbes, M. R. (2012). Shorebird incubation behavior and its influence on the risk of nest predation. Anim. Behav. 84, 835-842. doi: 10.1016/j.anbehav.2012.07.004

Stenseth, N. C., Mysterud, A., Ottersen, G., Hurrell, J. W., Chan, K.-S., and Lima, M. (2002). Ecological effects of climate fluctuations. Science 297, 1292-1296. doi: $10.1126 /$ science. 1071281

Takekawa, J. Y., and Warnock, N. D. (2020). "Long-billed Dowitcher (Limnodromus scolopaceus), version 1.0," in Birds of the World, eds A. F. Poole and F. B. Gill (Ithaca, NY: Cornell Lab of Ornithology).

Taylor, A. R., Lanctot, R. B., and Holmes, R. T. (2018). “An evaluation of 60 years of shorebird response to environmental change at Utqiagivik (Barrow), Alaska," in Trends and Traditions: Avifaunal Change in Western North America, eds W. D. Shuford, R. E. Gill Jr., and C. M. Handel (Camarillo, CA: Studies of Western Birds 3), 312-330. doi: 10.21199/swb3.17

Tulp, I., and Schekkerman, H. (2006). Time allocation between feeding and incubation in uniparental arctic-breeding shorebirds: energy reserves provide leeway in a tight schedule. J. Avian Biol. 37, 207-218. doi: 10.1111/j.2006.09088857.03519.x

Tulp, I., and Schekkerman, H. (2008). Has prey availability for Arctic birds advanced with climate change? Hindcasting the abundance of tundra arthropods using weather and seasonal variation. Arctic 61, 48-60. doi: 10. 14430/arctic6

Walther, G.-R., Post, E., Convey, P., Menzel, A., Parmesan, C., Beebee, T. J. C., et al. (2002). Ecological responses to recent climate change. Nature 416, 389-395.

Ward, D. H., Helmericks, J., Hupp, J. W., McManus, L., Budde, M. E., Douglas, D. C., et al. (2016). Multi-decadal trends in spring arrival of avian migrants to the central Arctic coast of Alaska: effects of environmental and ecological factors. J. Avian Biol. 47, 197-207. doi: 10.1111/jav.00774

Wauchope, H. S., Shaw, J. D., Varpe, Ø, Lappo, E. G., Boertmann, D., Lanctot, R. B., et al. (2016). Rapid climate-driven loss of breeding habitat for Arctic migratory birds. Glob. Change Biol. 23, 1085-1094. doi: 10.1111/gcb.13404

Weiser, E. L., Brown, S. C., Lanctot, R. B., Gates, H. R., Abraham, K. F., Bentzen, R. L., et al. (2018a). Effects of environmental conditions on reproductive effort and nest success of Arctic-breeding shorebirds. IBIS 160, 608-623.

Weiser, E. L., Brown, S. C., Lanctot, R. B., Gates, H. R., Abraham, K. F., Bentzen, R. L., et al. (2018b). Life-history tradeoffs revealed by seasonal declines in reproductive traits in Arctic-breeding shorebirds. J. Avian Biol. 49:e01531.

White, G. C., and Burnham, K. P. (1999). Program MARK: survival estimation from populations of marked animals. Bird Stud. 46, S120-S139.

Williams, S. E., Shoo, L. P., Isaac, J. L., Hoffmann, A. A., and Langham, G. (2008). Towards an integrated framework for assessing the vulnerability of species to climate change. PLoS Biol. 6:e325. doi: 10.1371/journal.pbio.0060325

Wrubleski, D. A., and Rosenberg, D. M. (1990). The Chironomidae (diptera) of bone pile pond, Delta Marsh, Manitoba, Canada. Wetlands 10, 243-275. doi: $10.1007 / \mathrm{bf} 03160835$

Conflict of Interest: The authors declare that the research was conducted in the absence of any commercial or financial relationships that could be construed as a potential conflict of interest.

The authors declare that this study received funding from BP Exploration (Alaska) Inc. The funder was not involved in the study design, collection, analysis, interpretation of data, the writing of this article or the decision to submit it for publication.

Copyright (C) 2020 McGuire, Lanctot, Saalfeld, Ruthrauff and Liebezeit. This is an open-access article distributed under the terms of the Creative Commons Attribution License (CC BY). The use, distribution or reproduction in other forums is permitted, provided the original author(s) and the copyright owner(s) are credited and that the original publication in this journal is cited, in accordance with accepted academic practice. No use, distribution or reproduction is permitted which does not comply with these terms. 